\title{
Numerical Prediction of Homogeneity of Gas Flow through Perforated Plates
}

\author{
Kamil Śmierciew ${ }^{1, * \mathbb{D}}$, Dariusz Butrymowicz ${ }^{1}$, Jarosław Karwacki ${ }^{2}$ and Jerzy Gagan ${ }^{1}$ \\ 1 Department of Heat Technology, Bialystok University of Technology, Wiejska 45C, 15-351 Bialystok, Poland; \\ d.butrymowicz@pb.edu.pl (D.B.); j.gagan@pb.edu.pl (J.G.) \\ 2 Deparment of Heat Transfer, The Szewalski Institute of Fluid-Flow Machinery Polish Academy of Sciences, \\ 80-231 Gdansk, Poland; j.karwacki@imp.gda.pl \\ * Correspondence: k.smierciew@pb.edu.pl; Tel.: +48-571-443-096
}

Citation: Śmierciew, K.;

Butrymowicz, D.; Karwacki, J.;

Gagan, J. Numerical Prediction of Homogeneity of Gas Flow through Perforated Plates. Processes 2021, 9, 1770. https://doi.org/10.3390/ pr9101770

Academic Editor: Paola Ammendola

Received: 30 August 2021

Accepted: 27 September 2021

Published: 2 October 2021

Publisher's Note: MDPI stays neutral with regard to jurisdictional claims in published maps and institutional affiliations.

Copyright: (c) 2021 by the authors. Licensee MDPI, Basel, Switzerland. This article is an open access article distributed under the terms and conditions of the Creative Commons Attribution (CC BY) license (https:/ / creativecommons.org/licenses/by/ $4.0 /)$.
Abstract: Vanes and baffles are often used as flow distributors where uniform flow is required in the apparatus of large cross-section surface areas. As an alternative, perforated plates with a range of open area ratios are applied to produce required gas flow homogeneity. Usually, the plates with various open area ratios are combined into large panels, of which total surface area can reach hundreds of square meters for large-sized industrial apparatus. Numerical modelling of the flow through such panels can be thought of as overly complex, time-consuming, and inefficient due to numerous small open area ratios in the plates and large differences in dimensions between open area ratios and free-stream areas. For this reason, numerical models of gas flow are limited to single plates only with constant open area ratios. A new indirect modelling approach of gas flow through the perforated plates panel with structural elements and various open area ratios with application of the porous media model is proposed. A perforated plate was experimentally investigated in terms of pressure drop and velocity distribution. The data obtained were used for the validation of the numerical results, which differed from the experimental results by less than $5 \%$. In the next step, numerical analyses were performed for plates with open area ratios in the range of 30 to $70 \%$ for gas velocities of 5 and $10 \mathrm{~m} / \mathrm{s}$. A general correlation for pressure drop as a function of open area ratio was proposed. Finally, systematic numerical studies of the flow through both perforated and porous plates including structural elements were performed. The internal resistance of the porous core was calculated by means of a developed correlation. A good agreement between results with an error lower than $15 \%$ was observed.

Keywords: flow homogeneity; porous model; perforated plate; CFD; velocity distribution

\section{Introduction}

Many industrial and chemical processes require uniform velocity distribution. Independently of an analysed process, flow uniformity may be thought of as a condition required for the effective operation of various types of large industrial apparatus. For heat exchangers, cleaning processes, air-conditioning systems, textile or drying industries, aeronautics, hydraulics, pharmaceutics, fuel cells, fuel processing chemical reactors, etc., it is of great importance to provide as high a homogeneous flow as possible [1-3]. Special attention is usually paid to this problem for the gas flow through the apparatus of a large cross-section surface area. A uniform flow distribution often has further advantages in improving the mass transfer, controlling the temperature, decreasing the pressure loss, decreasing the energy consumption, reducing the mass and dimensions of the system, reducing toxic components and reducing noise. In the case of low volumetric air flows, the homogenization process is not a major problem. However, it is a great challenge for devices with very large volumetric gas flows and resulting large cross-section surface areas. In general, uniform flow distribution creates a major problem for large-scale systems, e.g., scrubbers, filters, and cleaning systems in power stations. For example, pollutant 
removal is one of the key engineering processes, the purpose of which is to eliminate toxic components and to isolate valuable components that may remain in production processes. Particulates are basically dust particles that appear as smoke during the burning of some fossil fuels (or wood). They are relatively unimportant for the combustion of oil, gasoline, and natural gas, but they are much more significant during the combustion of coal.

The above requirements are of special importance for exhaust gas cleaning systems using mechanical filters (baghouses) or electrostatic precipitators (ESP). In the past few years, researchers have shown considerable interest in the latter, especially in terms of using CFD. Therefore, in this paper, the literature survey will mostly cover papers dealing with electrostatic precipitators as a perfect example of large-scale systems, and the utility of the proposed method will also be explained using ESP. However, the proposed numerical modelling approach may be applied for any other system or process which required flow uniformity.

Regardless of the used technology, the high efficiency of gas cleaning may be thought of as a necessary condition for the further operation of fossil fuel power plants. For larger particles, the efficiency of gas cleaning can be as high as $99.9 \%$ [4]. The dedusting efficiency decreases with the reduction in the particulate matter size. In a small particle size range in the order of 2.5 microns, power plants are being forced to apply techniques to improve the further control of fine particle emissions. The new, restrictive best available technology (BAT) requirements that will enter into force after 2021 clearly define the need to take measures to adapt the existing and build new flue gas treatment installations [5]. The following possible solutions are regarded: (i) modernization-increasing the electrostatic precipitator settlement area and renovation of the existing chamber and internal equipment; (ii) the use of various types of discharge electrodes; (iii) improving the velocity distribution and homogeneity of the exhaust gas flow in the electrostatic precipitator based on CFD simulations; (iv) replacement or modification of control systems and/or power units. This paper deals with the third discussed solution.

The performance of many industrial or chemical processes strongly depends on the complex gas flow distribution. The gas cleaning process also depends on the capture performance of fly ash particles. Usually, the flow is very turbulent; the Reynolds number exceeds the value of $\operatorname{Re}>10^{5}$ [6]. The velocity distribution influences turbulence in the vicinity of the collecting electrodes. The unfavourable velocity distribution affects the uneven turbulence, which translates into the collective capacity of the electrostatic precipitator.

Usually, in order to organize the flow in the ESP, diffusers are used upstream of the dedusting chamber. The large collecting chamber with hoppers is connected with channels by the diffuser (intake) and the contractor (exhaust). Inside the chamber, the electrodes are fixed. Perforated plates are mounted inside the diffuser. Usually, the plates are combined into one large panel. Depending on the size of the ESP, one panel can contain up to several dozen plates. The open area ratio of the panel is defined as follows:

$$
f=\frac{A_{O}}{A_{C}}
$$

where $A_{O}$ is the overall surface area of holes in the plate and $A_{C}$ is the overall surface area of the plate. The plate open area ratio usually varies between 0.3 and 0.7 .

Depending on the dimensions of the diffuser and the plates arrangement in the diffuser, the angle of inflow of the gas stream to the surface of the plate may vary from $30^{\circ}$ to about $90^{\circ}$. The gas velocity distribution in the ESP thus plays an important role in the overall performance of the ESP. The velocity distribution in the ESP should be in accordance with the ICAC-EP7 [7] standard. Too high local gas velocities may cause the aerodynamic forces of the particles to exceed the electrostatic forces generated by the collecting surfaces and electrodes. This leads to a reduction in the separation efficiency. Likewise, if the local velocities are too low, the collecting surface is not properly utilised and the potential for particle build-up in the ESP inlet and outlet channels increases. Perforated plates of low porosity tend to diverge in flow, causing flux to accumulate near the walls. On the other 
hand, perforated plates of high porosity have a poor flow distribution. In this case, a high speed near the axis can be expected. Placing the plates close together will not improve the gas flow distribution; on the contrary, the effect will be the opposite. Additionally, fixing the plates at the exit of the diffuser is not recommended because of the distance the gas flow has to travel before it can adjust and smooth out the vortices formed behind the perforated plate. Thus, determination of the plates' locations and the degree of the plate's open area ratio requires multi-variant analyses based on CFD that are not feasible in real conditions.

\section{Previous Studies of Modelling of Flow through Perforated Plates}

As already mentioned, electrostatic precipitators are a good example of large-scale units, and extensive research has been carried out for this particular type of apparatus. Numerical modelling of the flow distribution inside the ESP allows us to achieve the best collecting performance of the electrostatic precipitator $[8,9]$. Such studies have been used to investigate the air flow in the presence of an electrostatic field [10,11], and authors have captured the effect of the electric field by adding a source term in the momentum equation. The 2D model that takes into consideration all the processes involved inside an industrial ESP, which are the fully coupled to three coexisting fields of gas flow, particle dynamics, and electrostatics, has been presented by Scodras et al. [12]. The effect of corona charging and particle collection with a simple 3D model have been studied by Arif et al. [13]. The effect of interactions between the electrical field and passing air is usually studied with a simplified model of small samples of ESP reduced to few electrodes. Numerical investigations of flow through the perforated plate were conducted by Guo et al. [14]. These authors have studied flow structure around a single hole of the perforated plate. Authors have found that local eddy downstream of the plate is the main cause of pressure loss. Effects of air inlet velocity magnitude on the velocity distribution in ESP was investigated by Yusop et al. [15]. Again, a 2D CFD model was used in their investigations. Similar investigations in terms of velocity distribution in ESP were conducted by Kouropoulos [16]. Celik et al. [17] in their own numerical investigations have found that porosity of the plate is the most effective design parameter in terms of pressure drop across the plate, while the least effective is the hole pattern. However, due to numerous small open area ratios in the plate and large differences in dimensions reaching at least two orders of magnitudes, the perforated plates located in the ESP can be considered as very complex geometry. Numerical simulation of the entire ESP including chamber, hoppers, a piping system with turning vanes, plates, etc. is inefficient, impractical, and extremely costly. It must be pointed out that this geometrical model would require very precise computational mesh to capture the boundary layer and the huge number of the holes in the plates. Additionally, due to flow complexity, the simulation in time-dependent conditions seems to be more favourable. Taking into consideration the time expenditure and requirements for the grid quality, solving the case with several dozens of millions of computational cells becomes unprofitable due to the significant time and numerical costs. For this reason, the steady state numerical simulation has been proposed to be applied $[18,19]$. However, this in turn is associated with an inevitable error in the velocity profile prediction for the unstable flow behind the perforated plate. Velocity distribution behind the perforated plate of the open area ratio 0.50 located in the diffuser in ESP using the porous material model was numerically investigated by Swaminathan and Mahalakshimi [3].

An indirect modelling of the perforated plate with application of the porous media model is proposed in this paper. Two novelties have been provided in this paper: the first one is an attempt to develop a universal approach of modelling of the perforated plates of various open area ratios, and the second novelty is related to the structural elements applied between plates. As was stated previously, in large-scale systems the panels consist of several dozens of perforated plates connected with structural elements. Investigations presented in the literature usually cover one plate and neglect the presence of the structural elements, which in many cases leads to incorrect flow prediction, which is general motivation for the present research. It is worthy to note that the proposed approach 
focuses on a practical and easy-to-apply method where the rough similarity of the flow with acceptable accuracy is important, rather than detailed statistical analysis. The proposed approach is aimed directly at designers and engineers involved in the design, optimisation, and operation of flow systems with complex geometry for the quick evaluation of different configurations and flow cases.

\section{Materials, Methods and Procedure}

The proposed modelling approach was tested for the plates with the following open area ratios: $0.30,0.35,0.40,0.44,0.50$ and 0.55 (circle open area ratios, $D=60 \mathrm{~mm}$ ); 0.60 and 0.69 (rectangle open area ratios, $97 \times 87 \mathrm{~mm}$ and $146 \times 148 \mathrm{~mm}$, respectively). The research plan applied to produce the modelling approach is presented in Table 1.

Table 1. Research plan.

\begin{tabular}{|c|c|c|}
\hline & Procedure, Type of Studies & Effect \\
\hline 1 & Initial numerical studies of single plate, $f=0.30$ & estimation of the flow disturbances \\
\hline 2 & experimental investigation of single plate, $f=0.40$ & $\begin{array}{l}\text { experimental results database: pressure drop, } \\
\text { velocity distribution }\end{array}$ \\
\hline 3 & numerical studies of single plate, $f=0.40$ & $\begin{array}{l}\text { numerical results database: pressure drop, } \\
\text { velocity distribution }\end{array}$ \\
\hline 4 & comparison of numerical and experimental results & data statistics (Figure 5, Figure 6 and Figure 7) \\
\hline 5 & numerical studies of the plate with different open area ratios & $\begin{array}{l}\text { numerical results database: pressure drop, velocity } \\
\text { distribution, coefficient } C_{2} \text { (Tables } 4 \text { and 5) }\end{array}$ \\
\hline 6 & development of correlation for pressure drop for all plates & correlation for pressure drop (Equation (11)) \\
\hline 7 & $\begin{array}{l}\text { numerical studies of the porous plate using } \\
\text { developed correlation }\end{array}$ & data statistics (Figure 8 and Figure 9) \\
\hline 8 & $\begin{array}{l}\text { numerical studies of the perforated panel with different } \\
\text { open area ratios including structural elements }\end{array}$ & $\begin{array}{l}\text { numerical results database: pressure drop, velocity } \\
\text { distribution (Table 6, Figure 12, Figure 13, Figure } \\
\qquad 14 \text { and Figure 15) }\end{array}$ \\
\hline 9 & $\begin{array}{l}\text { numerical studies of the porous panel including } \\
\text { structural elements }\end{array}$ & $\begin{array}{c}\text { numerical results data base: pressure drop, } \\
\text { velocity distribution (Table 6, Figure 12, Figure 13, } \\
\text { Figure } 14 \text { and Figure 15) }\end{array}$ \\
\hline 10 & validation of results: perforated panel vs. porous panel & data statistics, general conclusions \\
\hline
\end{tabular}

\subsection{Modelling Approach}

The main assumption in modelling was the application of porous material instead of the perforated plate. The porous zone is described by the source term added to the momentum equation [20]:

$$
\frac{\partial}{\partial t}(\rho \vec{u})+\nabla \cdot(\rho \vec{u} \vec{u})=-\nabla p+\nabla \cdot(\overline{\bar{\tau}})+p \vec{g}+\vec{F},
$$

where

$$
(\overline{\bar{\tau}})=\mu\left[\left(\nabla \vec{u}+\nabla \vec{u}^{T}\right)-\frac{2}{3} \nabla \cdot \vec{u} I\right]
$$

The source term in the momentum equation is as follows:

$$
S_{i}=-\left(\sum_{j=1}^{3} D_{i j} \mu u_{j}+\sum_{j=1}^{3} C_{i j} \frac{1}{2} \rho|u| u_{j}\right)
$$

where $S_{i}$ is the source term in momentum equation $(i=x, y$ or $z),|u|$ is the velocity module and $D_{i j}$ and $C_{i j}$ are the given matrices. In the above equation, the viscosity losses (Darcy's 
law) — the first term on the right-hand side of this equation, and the internal losses- the second term on the right-hand side of Equation (4), are included.

The momentum loss relates to the pressure gradient in porous media. Pressure loss is proportional to the velocity of the flow; however, for homogenous porous materials it is:

$$
S_{i}=-\left(\frac{\mu}{\alpha} u_{i}+C_{2} \frac{1}{2} \rho|u| u_{i}\right),
$$

where $\alpha$ is permeability and $C_{2}$ is the coefficient of internal resistance per unit thickness. It should be noted that in Equation (4), $D_{i j}$ and $C_{i j}$ are diagonal matrices with $1 / \alpha$ and $C_{2}$, respectively, on the main diagonal and zeros for rest of the entries.

In laminar flow, through the porous material the pressure drop is directly proportional to velocity and the $C_{2}$ coefficient can be omitted. Ignoring convective and diffusive phenomena, the model of the flow in porous material is reduced to Darcy's law:

$$
\nabla p=-\frac{\mu}{\alpha} \vec{u}
$$

For higher flow velocity, the coefficient $C_{2}$ takes into account the losses generated by the internal resistance. This coefficient can be considered as a loss coefficient in reference to length in flow direction. In the case of the perforated plate (a substitute for porous material) the permeability term might be omitted and a term representing only internal resistance can be used. This leads to:

$$
\nabla p=-\sum_{j=1}^{3} C_{2 i j}\left(\frac{1}{2} \rho u_{j}|u|\right),
$$

or considering all directions $x, y, z$, changes in pressure $\Delta p$ are:

$$
\begin{aligned}
\Delta p_{x} & \approx \sum_{j=1}^{3} C_{2 x j} \delta_{x} \frac{1}{2} \rho u_{j}|u|, \\
\Delta p_{y} & \approx \sum_{j=1}^{3} C_{2 y j} \delta_{y} \frac{1}{2} \rho u_{j}|u|, \\
\Delta p_{z} & \approx \sum_{j=1}^{3} C_{2 z j} \delta_{z} \frac{1}{2} \rho u_{j}|u| .
\end{aligned}
$$

The main idea for the substitution of a perforated plate with porous material is to find performance characteristics of porous material as the dependence of the pressure drop on flow velocity. In the CFD code used in present simulations, the porous material is described by three terms, namely: porosity $P$ (scalar), permeability $\alpha$ and coefficient of internal resistance $C_{2}$ (both are vectors). Porosity represents the void fraction, which measures the empty spaces in an observed volume of material. In the case of a perforated plate, all the holes are cylindrical, and the porosity results equal the value of the open area ratio $f$. The pressure drop $\Delta p$ across the plate $\delta$ was calculated by the following equation:

$$
\frac{\Delta p}{\delta}=\frac{\mu}{\alpha} u+\frac{1}{2} C_{2} \rho u^{2}
$$

\subsection{Validation Apparatus and Procedure}

\subsubsection{The Testing Stand}

The testing bench for experimental studies of changes in velocity distributions and pressure drops on the tested plates consists of a fan, an air-flow channel and measurement and data acquisition systems. The schematic diagram of the stand is presented in Figure 1. 

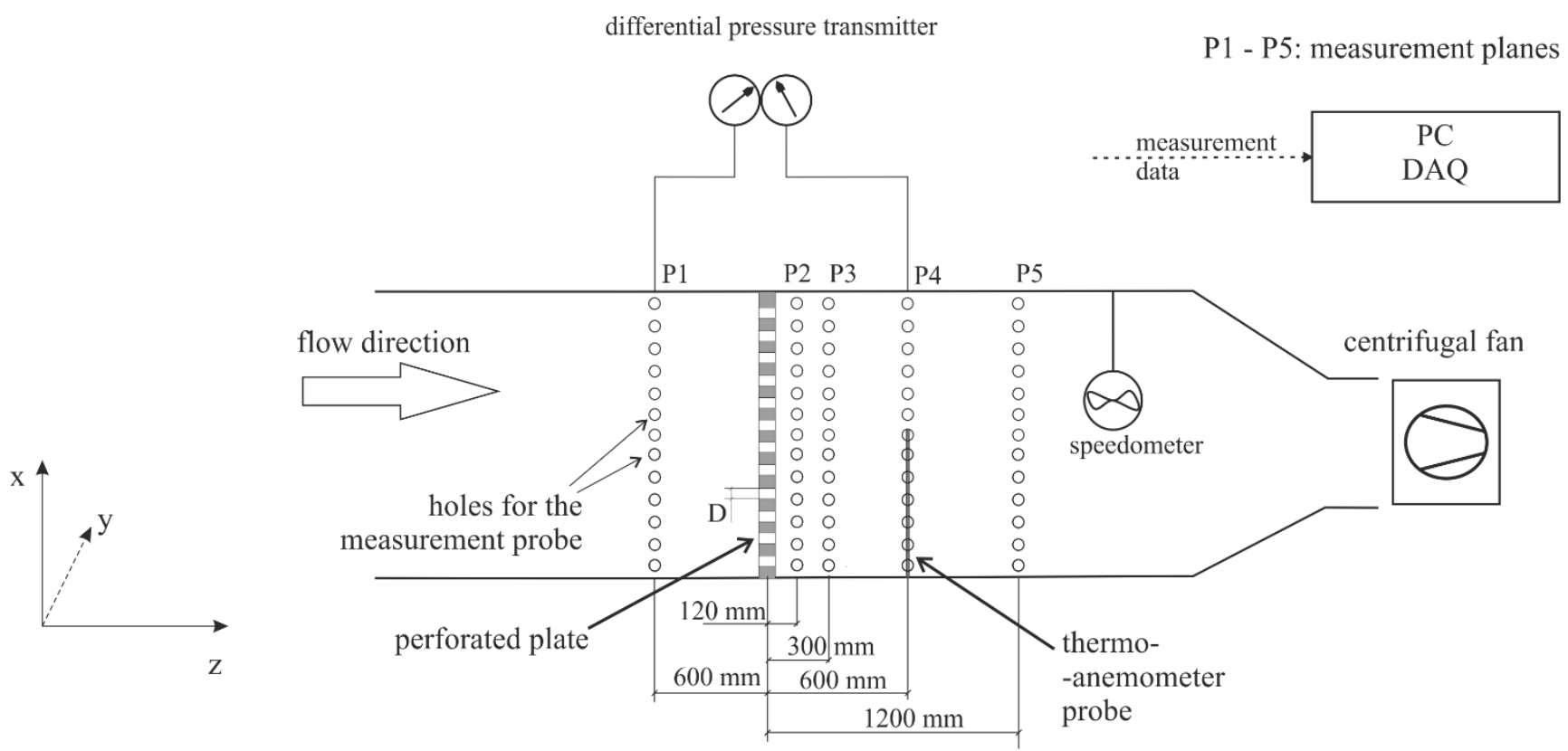

Figure 1. Schematic of the test channel.

The tested perforated plate was placed in the channel. The flow through the channel was generated by a radial fan driven by a motor power of $22 \mathrm{~kW}$. The fan flow capacity is controlled by changing of the rotational speed of the drive motor in the range of 20 to $100 \%$. The pressure drop measurements and velocity distributions were carried out. The distance between the perforated plate and measurement test plane was determined based on initial CFD studies. Simulations of the air flow through the plate with open area ratios of 0.30 were performed for estimation of the flow disturbances. This plate was selected because it has the lowest open area ratio surface area that produces the largest pressure drop and generates the most turbulent flow. The distances between the plate and test plane equal to $2 D, 5 D, 10 D$, and $20 D$ behind the plate, where $D=60 \mathrm{~mm}$ denotes the plate hole diameter that was used in experiments. Finally, the measurement devices for pressure and velocity were located at a distance of $10 \mathrm{D}$ behind the perforated plate.

The pressure was measured using the differential method, i.e., by the measurement of the static pressure at two planes: in front of the plate and behind the plate (both distances are 10D). A system of 5 measurement nozzles (flanges) placed in the side walls of the test channel was used. Thus, the measurement of the static pressure drop was carried out as a measurement of the averaged static pressure at the channel wall. The measurements were made with the use of a pressure difference transducer, the measurement accuracy of which is $\pm 0.075 \%$ of the measurement range. This means that the maximum systematic error of the sensor measurement used in the tests was $0.15 \mathrm{~Pa}$. The velocity field was measured in front of and behind the perforated plate (both distances are 10D). The measurements were performed with the use of a thermoanemometric probe, model 8455-225 of TSI Inc. In the velocity range of $10 \mathrm{~m} / \mathrm{s}$, the accuracy of a thermoanemometer is $0.05 \mathrm{~m} / \mathrm{s}$. The measurements were carried out at 195 different locations of the probe given by matrix $M_{m, n}$ where $m=15$ and $n=13$ are columns and rows along the $x$ and $y$ axes. The thermoanemometer registered approximately 200 samples, which were time-averaged; then, the probe was manually moved from one point to another. Additionally, at $1300 \mathrm{~mm}$ behind the plate a vane probe, model 435 of TESTO, was used for velocity measurements as it is seen in Figure 1. This measurement provided additional information about the fan operation. Temperature and relative humidity of air were also measured. It was observed that changes in temperature were in the range of $19.8-21.6{ }^{\circ} \mathrm{C}$ while the relative humidity was in the range of $65-75 \%$. We decided to neglect changes in air temperature and relative humidity 
in these investigations. A data acquisition system based on the National Instrument SCXI standard with LabVIEW software was applied in experiments.

\subsubsection{Single Plate Modelling}

Simulations for estimation of the flow disturbances were carried out for the plate of the open area ratio $f$ of 0.30 . However, the proper simulation of the air flow through the channel was performed for the plate of the open area ratio $f=0.40$. This plate was provided by the ESP manufacturer for the experimental investigations [21]. This case can be treated as representative of the analysed range of geometries as it has an intermediate degree of open area ratio. The dimensions of the single plate are $1230 \times 875 \times 4 \mathrm{~mm}$. A geometrical representation of the test tunnel is shown in Figure 2. The full 3D geometrical model contains of all the structural details inside the tunnel. Additionally, part of the exterior area of the tunnel was included in model. By this means, the inlet conditions were more realistic and allow to avoid the assumption of the uniform profile at the inlet of the tunnel.

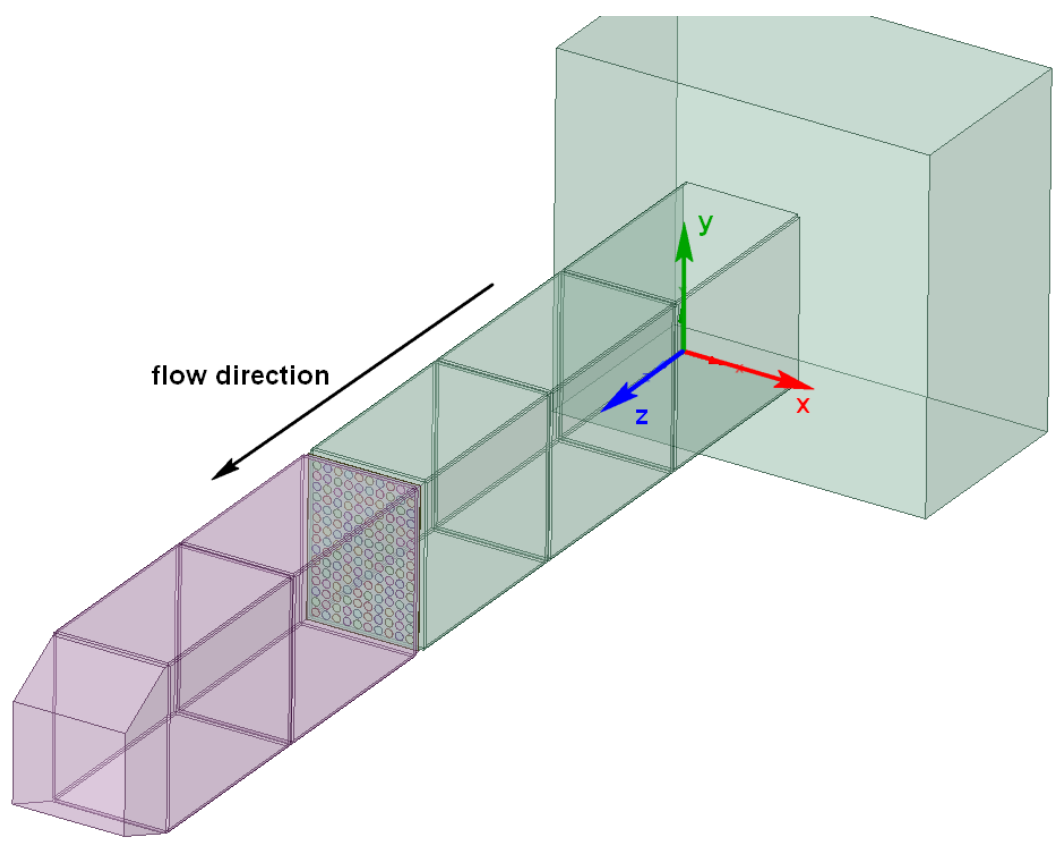

Figure 2. Geometrical representation of the test channel.

The model was discretised with unstructural mesh. More dense parts of the mesh were generated in the vicinity of the plate. Mesh independence studies have been carried out to estimate the total number of computational cells to eliminate the dependence of the results on the mesh density. For given inlet velocity $v_{i n}=5 \mathrm{~m} / \mathrm{s}$ the pressure drop $\Delta p$ was calculated for a different number of cells (see Table 2). Mesh-independent studies reveal that approximately 2.7 million of cells would be the best case, because with further increasing the mesh density, the changes in the results are negligible. Ansys Fluent solver was used. General assumptions for these studies were as follows:

- the flow was at the steady state condition;

- air was treated as an incompressible gas of density $1.225 \mathrm{~kg} / \mathrm{m}^{3}$;

- air is free from ash, dust, or any other particles;

- there was no presence of electrostatic field or other acting sources, except gravitational force;

- temperature of air does not change. 
The above assumptions are commonly applied for modelling of flow distribution systems for ESP $[3,8,15,19]$. The turbulence model $\mathrm{k}-\mathrm{\omega}$ was applied for the discussed case of flow distributor [22].

In this case, pressure inlet $p_{\text {in }}$ and pressure outlet $p_{\text {out }}$ were set as the boundary conditions; therefore, velocity was treated as a sought parameter. Several cases were calculated for $\Delta p_{B C}=p_{\text {in }}-p_{\text {out }}$ in range of 20-700 Pa. The temperature of air was $300 \mathrm{~K}$ for all tested cases presented in this paper. Obtained results were used for experimental validation. They are presented in Figure 5.

Table 2. Results of mesh independence tests.

\begin{tabular}{cccc}
\hline Mesh No. & Number of Cells & Pressure Drop, $\Delta \mathbf{p}[\mathbf{P a}]$ & $\frac{\Delta p_{n}-\Delta p_{n-1}}{\Delta p_{n}} \cdot 100 \%$ \\
\hline 1 & 280,640 & 138.29 & - \\
2 & 518,090 & 141.86 & 2.52 \\
3 & 724,520 & 143.61 & 1.22 \\
4 & $1,438,303$ & 144.75 & 0.788 \\
5 & $2,685,433$ & 145.02 & 0.186 \\
6 & $4,103,286$ & 145.18 & 0.110 \\
\hline
\end{tabular}

In Figure 3, the pathlines inside the tunnel for $\Delta p_{B C}=p_{\text {in }}-p_{\text {out }}=145 \mathrm{~Pa}$ were shown. It shows the vortice creation behind the perforated plate.

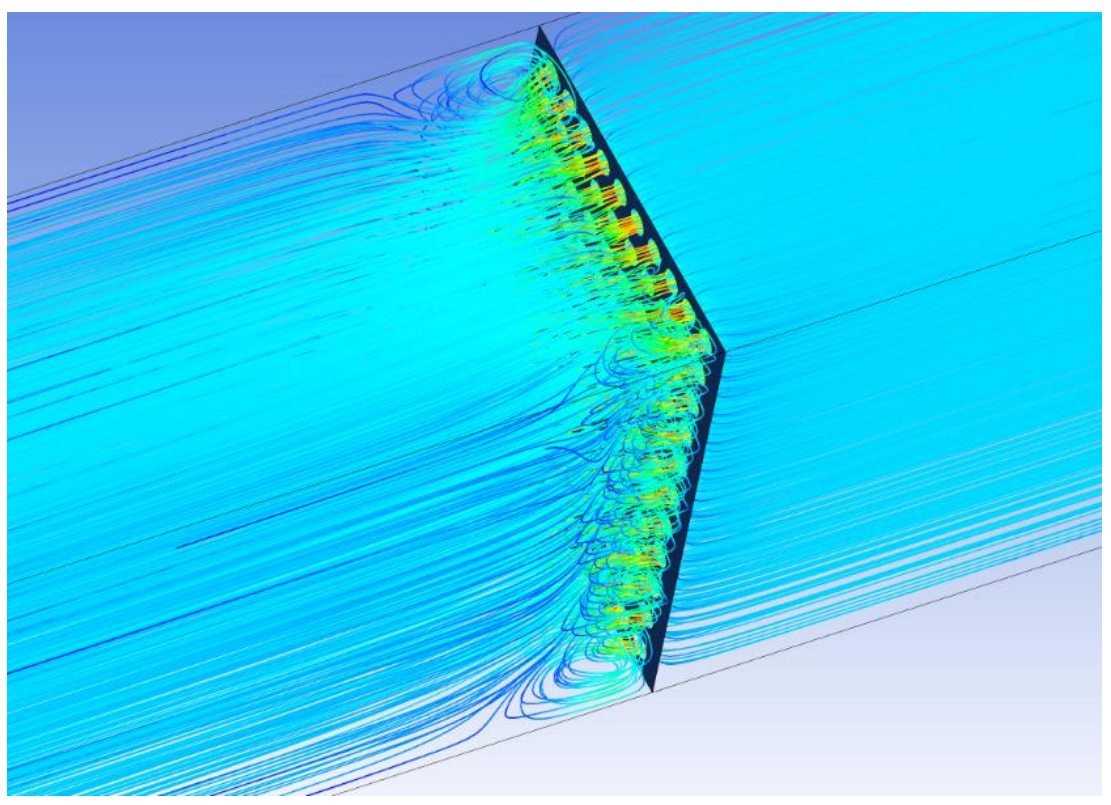

Figure 3. Pathlines inside the tunnel for $\Delta p_{B C}=145 \mathrm{~Pa}$.

In Figure 4, the velocity fields at different planes are shown. The velocity before the plane (P1) and behind the plate at the plane P2 are shown. The plane P1 is located at a distance of $10 D$ in front of the plate and P2 is located at a distance of $2 D$ behind the plate. Regardless that the plane P1 is not fully visible, the differences of the flow-field between the planes P2 and P1 are clear. Figure 4 also shows that the flow becomes uniform at the rest of the planes. 

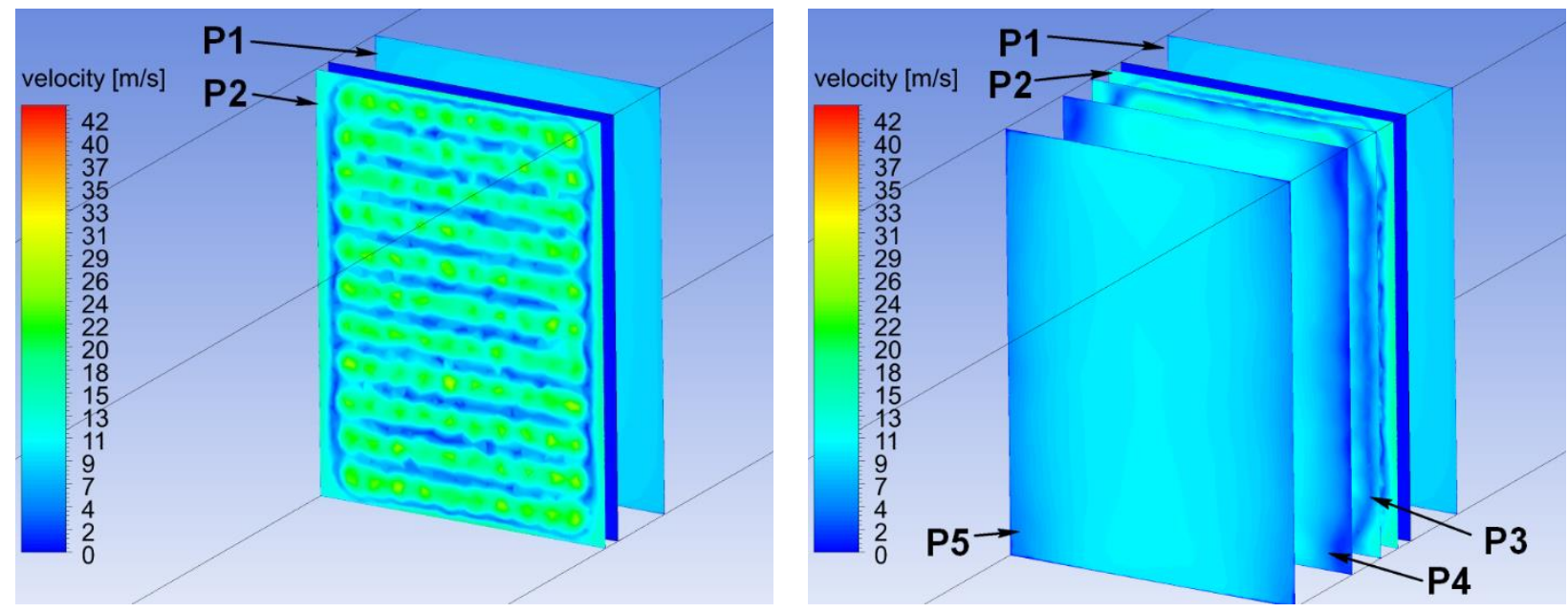

Figure 4. Velocity field at different planes for $\Delta p_{B C}=145 \mathrm{~Pa}$.

\subsubsection{Experimental Validation}

The experimental investigations were conducted for the plate with an open area ratio $f=0.40$ (see Section 3.2.2). The relationship between air velocity and pressure drop through the plate was compared. Four measurements were carried out for various fan speeds and resulting air flow velocities. Results were averaged using the area-weighted averaging method. Pressure differences between static pressure measured at the plane P1 and the plane P4, $\Delta p=p_{1}-p_{4}$, for each point were calculated and compared with the same pressure difference obtained from CFD. Results are shown in Table 3 and Figure 5. Relative error was calculated as follows

$$
R E=\frac{C F D-E X P}{C F D} \cdot 100 \%
$$

Table 3. Comparison of numerical and experimental results.

\begin{tabular}{ccccccc}
\hline Measurement No. & $\boldsymbol{\Delta} \boldsymbol{p}_{\text {EXP }}[\mathrm{Pa}]$ & $\boldsymbol{\Delta} \boldsymbol{p}_{\text {CFD }}[\mathrm{Pa}]$ & $\mathbf{R E}[\%]$ & $\boldsymbol{u}_{\mathrm{EXP}}[\mathrm{m} / \mathbf{s}]$ & $\boldsymbol{u}_{\text {CFD }}[\mathrm{m} / \mathbf{s}]$ & $\mathbf{R E}[\%]$ \\
\hline 1 & $53.93 \pm 1.28$ & 53.89 & -0.07 & $3.22 \pm 0.19$ & 3.34 & 3.73 \\
2 & $94.72 \pm 0.75$ & 95.26 & 0.57 & $4.37 \pm 0.20$ & 4.44 & 1.60 \\
3 & $125.59 \pm 1.84$ & 126.70 & 0.88 & $4.87 \pm 0.22$ & 5.12 & 5.13 \\
4 & $154.70 \pm 2.74$ & 156.06 & 0.88 & $5.72 \pm 0.22$ & 5.69 & -0.53 \\
\hline
\end{tabular}

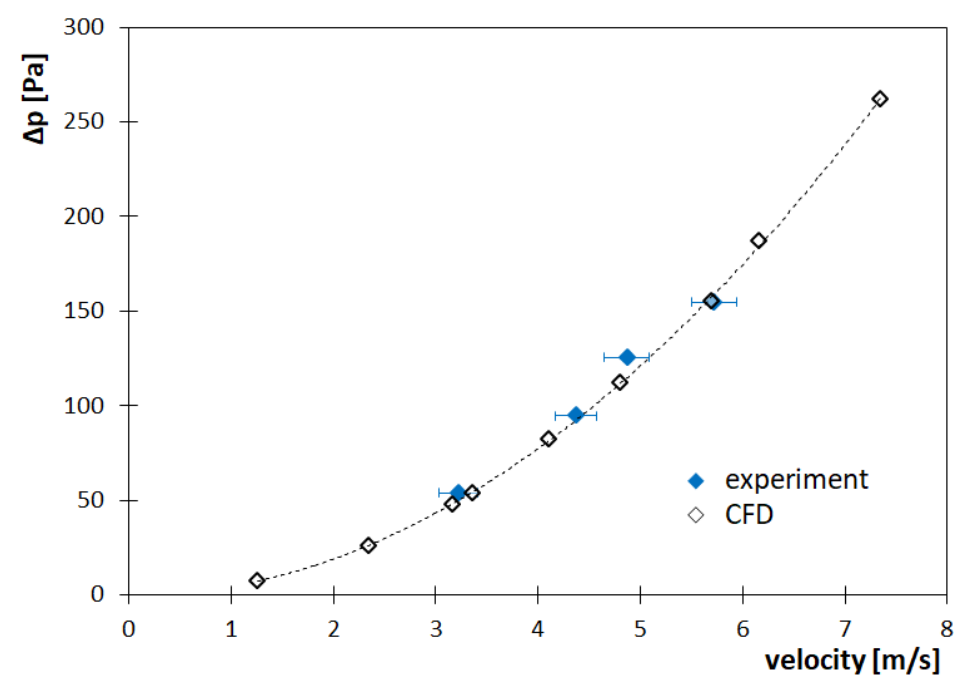

Figure 5. Comparison of numerical and experimental results. 
As seen, in Table 3 the numerical results fit well to experimental results. Pressure drop and mean velocity are slightly overpredicted by CFD simulation; however, the maximum relative error for velocity is $5 \%$ and lower than $1 \%$ for the pressure drop.

The results shown in Figure 6 indicate that the velocity profile obtained from CFD predicts the profile obtained from the experiment along the measurement lines well. As shown in Figure 7, the relative error between the obtained results is in the range of $\pm 15 \%$. It can be concluded that numerical simulation predicts pressure drop and velocity distribution with good accuracy.

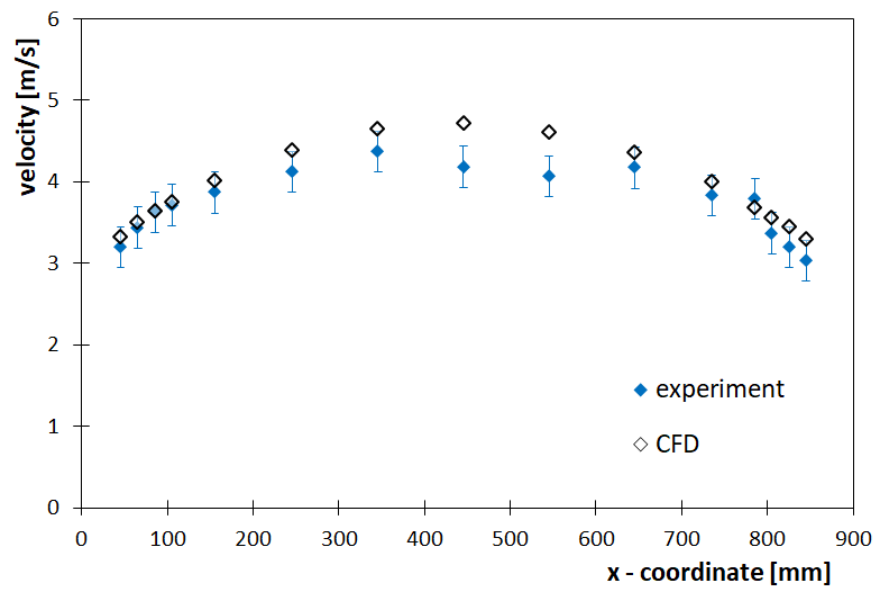

(a)

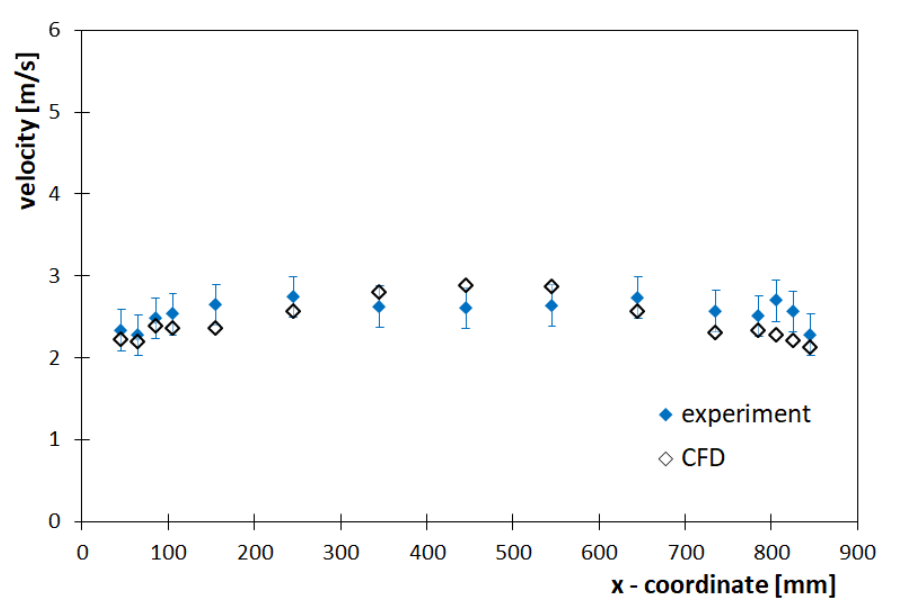

(b)

Figure 6. Velocity profile behind the plate: (a) for measurement row No.3 (y=218 mm); (b) for row No.6 (y=518 mm). Corresponding $\Delta p=100 \mathrm{~Pa}$.

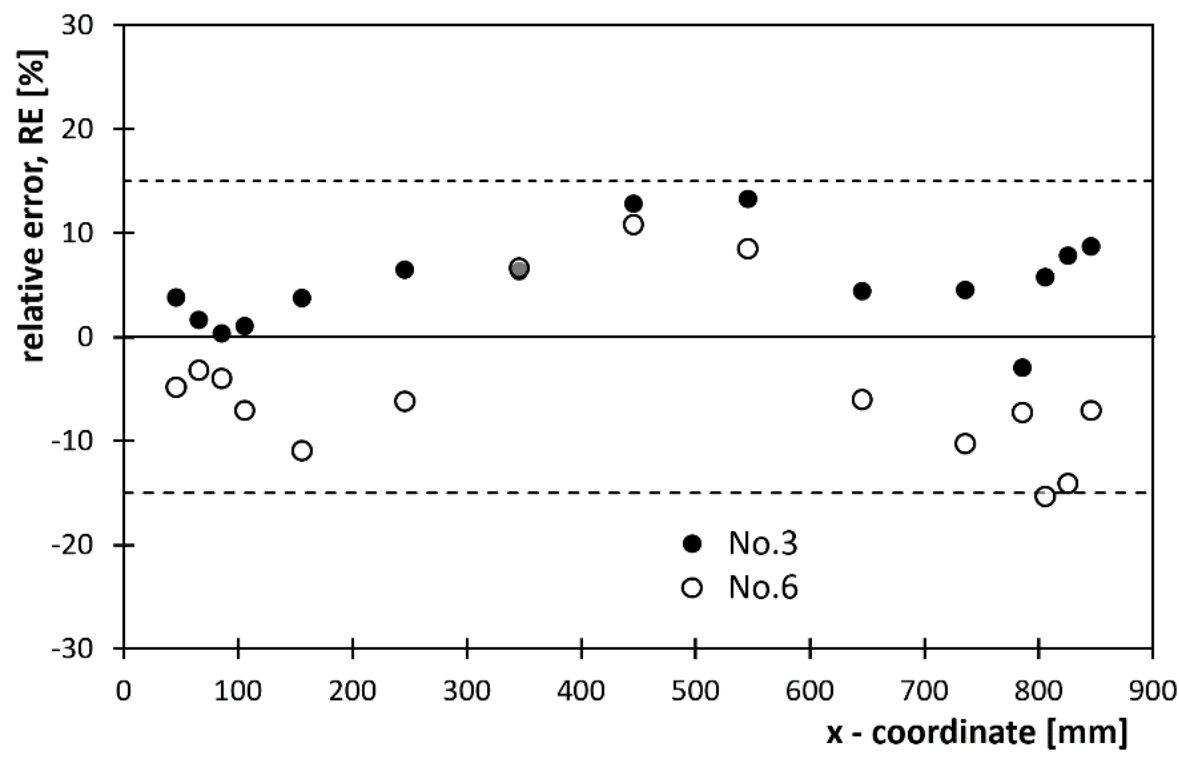

Figure 7. Relative error between numerical and experimental results shown in Figure 6 for measurement lines No.3 and No.6. 


\section{Results of Modelling of the Panels}

\subsection{Modelling of the Perforated Plates with Different Open Area Ratios}

Good accuracy between the numerical and experimental results of pressure drop and air velocity allows us to perform simulation for all analysed perforated plates. It should be emphasised that air flow in the test tunnel is not reliable for the simulation of flue gas flow inside the ESP. Under realistic conditions, walls do not affect the flow in such manner as in the test tunnel due to large distances between walls. Therefore, for calculation of the performance lines for perforated plates, periodic flow was taken into consideration. In the numerical model, the walls were set as periodic boundary conditions. By this means, we have captured the effect of repeatability of the plates and the boundary layer was eliminated. Calculations were performed for all investigated plates. General assumptions are given in the previous section. Numerical meshes for these cases contain 2.0-2.8 million ells, where the number of computational cells increases as the parameter $f$ increases. Velocity in the range of $1-10 \mathrm{~m} / \mathrm{s}$ with a step of $1 \mathrm{~m} / \mathrm{s}$ and outlet were set as the boundary conditions. In this calculation, the pressure drop was the resultant parameter. The calculated values of the pressure drop on the plate for the selected various velocities are presented in Table 4.

According to Equation (8), the pressure drop across the plate is related to the thickness of the plate $\Delta p / \delta$.

The pressure drops for each plate presented in Table 4 can be approximated with the following function:

$$
Y=A u+B u^{2},
$$

which is similar to Equation (8), where $Y=\Delta p / \delta, A=\mu / \alpha$ and $B=0.5 \rho C_{2}$. Approximation of pressure drop across the plate as a function of velocity gives the parameters $A$ and B. Taking dynamic air viscosity $\mu$ and density $\rho$, the coefficients $\alpha$ and $C_{2}$ can be found. Parameter A is at the order of magnitude of few or dozens. Therefore, on the basis of obtained coefficient $\mathrm{A}$, the value of the permeability $\alpha$ in the range of $0.8 \div 3.0 \times 10^{-6}$ could be found. For the analysed plates, $\Delta p / \delta$ (Equation (10)) mostly depends on the term $0.5 C_{2} \rho u^{2}$ (see Figure 5) and the term $\mu u / \alpha$ has a minor impact. Therefore, in this paper, the term $\mu u / \alpha$ was not taken into consideration for calculation of internal resistance coefficient $C_{2}$. Values of the internal resistance coefficient $C_{2}$ are presented in Table 5.

Table 4. Pressure drop for the tested plates for various velocities.

\begin{tabular}{cccccc}
\hline \multicolumn{7}{c}{ Velocity [m/s] } \\
\hline$f$ & $\mathbf{1}$ & $\mathbf{3}$ & $\mathbf{5}$ & $\mathbf{7}$ & $\mathbf{9}$ \\
\hline- & & & Pressure Drop [Pa] & \\
\hline 0.30 & 2515 & 22,648 & 62,926 & 123,351 & 203,923 \\
0.35 & 1527 & 13,718 & 38,092 & 74,648 & 123,385 \\
0.40 & 963 & 8634 & 23,963 & 46,948 & 77,589 \\
0.44 & 681 & 6087 & 16,886 & 33,076 & 54,654 \\
0.50 & 358 & 3140 & 8675 & 16,955 & 27,978 \\
0.55 & 263 & 2289 & 6305 & 12,306 & 20,289 \\
0.60 & 225 & 2009 & 5570 & 10,908 & 18,022 \\
0.69 & 134 & 1188 & 3291 & 6442 & 10,640 \\
\hline
\end{tabular}


Table 5. Values of internal resistance coefficient $C_{2}$.

\begin{tabular}{cc}
\hline Open Area Ratio & Coefficient $C_{\mathbf{2}}$ \\
\hline 0.30 & 4368.62 \\
0.35 & 2592.16 \\
0.40 & 1649.31 \\
0.44 & 1194.39 \\
0.50 & 774.76 \\
0.55 & 561.06 \\
0.60 & 417.88 \\
0.69 & 247.96 \\
\hline
\end{tabular}

\subsection{Modelling of Single Porous Plate}

Data from Table 4 were used to propose a general relationship between porosity and internal resistance:

$$
C_{2}=71.688 f^{-3.421} \text {. }
$$

The internal resistance of equivalent porous material for each tested perforated plate was found from Equation (11). The coefficient of determination $R^{2}=0.9998$. Once the internal resistance $C_{2}$ was found, the validation calculations were performed, in which the perforated plate was replaced by a porous core. The boundary conditions were the same as in Section 4.1. Numerical simulations were conducted for all plates (see Table 4). The plate with $f=0.4$ was comprehensively investigated in terms of pressure drop for velocities in the range of 1-10 m/s. Results are presented in Figure 8. As can be seen, the pressure drop obtained for the porous plate is lower by about $20 \%$ than for the perforated plate.

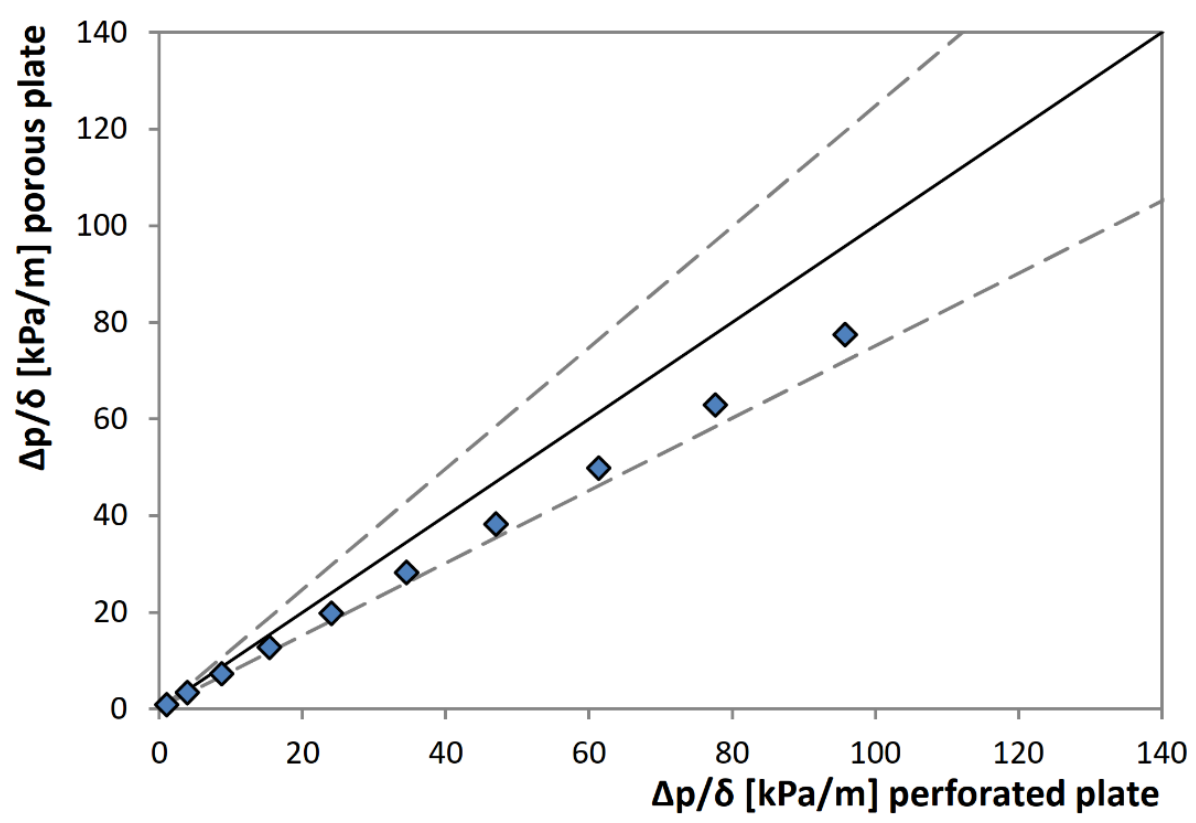

Figure 8. Comparison of pressure drop per depth of the plate for perforated and porous plates, $f=0.40$.

The rest of the tested plates substituted with corresponding porous material with $C_{2}$ calculated from Equation (11) were studied for two velocities: $u_{1}=5 \mathrm{~m} / \mathrm{s}$ and $u_{2}=10 \mathrm{~m} / \mathrm{s}$. The comparison between pressure drop for all tested cases is shown in Figure 9. The figure shows that for the rest of the tested plates, the same trend as for the plate of $f=0.40$ is observed. Again, the pressure drops obtained for the porous plates is lower by about $20 \%$ than for the corresponding perforated plates. 


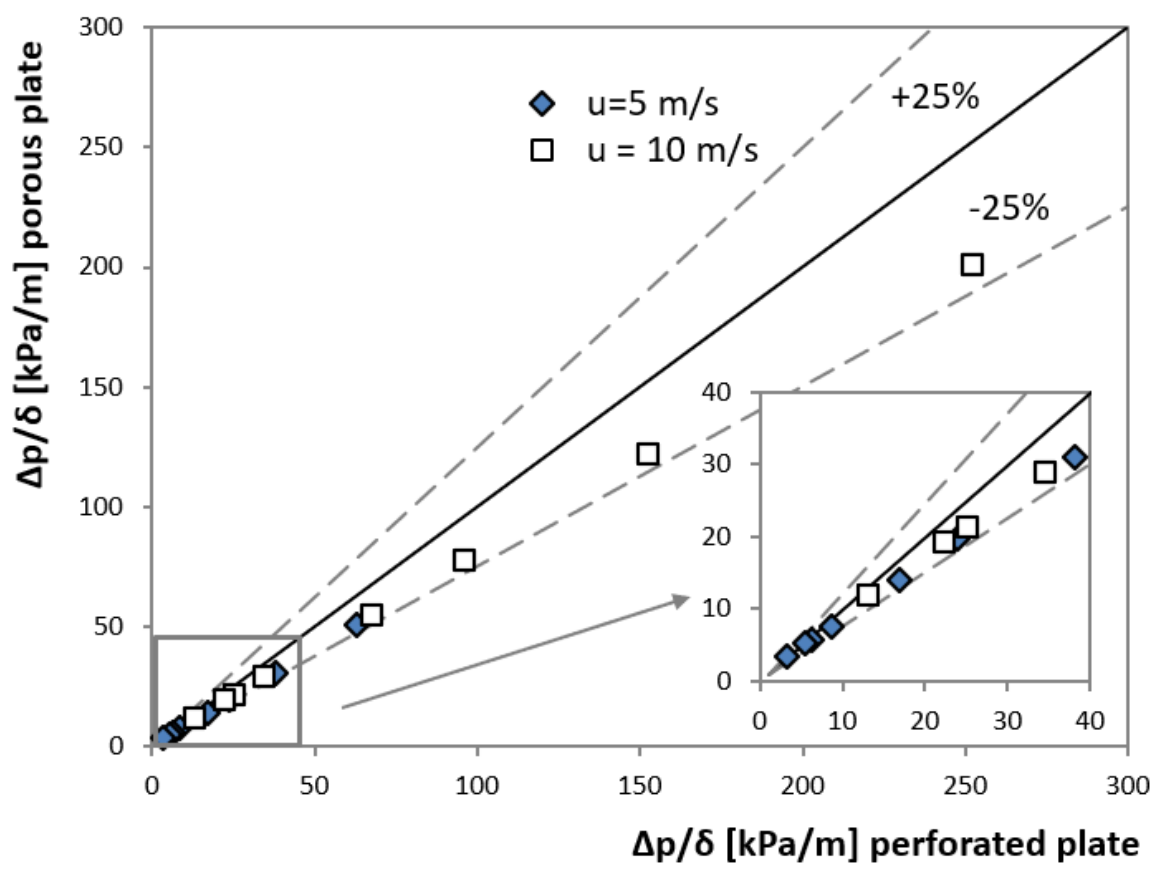

Figure 9. Comparison of pressure drop per depth of the plate for perforated and porous plates for all tested plates and two average velocities of air.

\subsection{Modelling of Test Panel Plate}

As previously stated, in the ESP one panel contains several perforated plates. Plates are connected by means of the structural elements. These elements affect the gas flow in the ESP. In the numerical simulation presented in this paper, the analysed panel containing four plates with structural elements was investigated. Walls were set as periodic boundary conditions. By this means, we have captured the effect of the repeatability of the plates. Part of the geometrical model for the case of $f=0.50$ is presented in Figure 10.

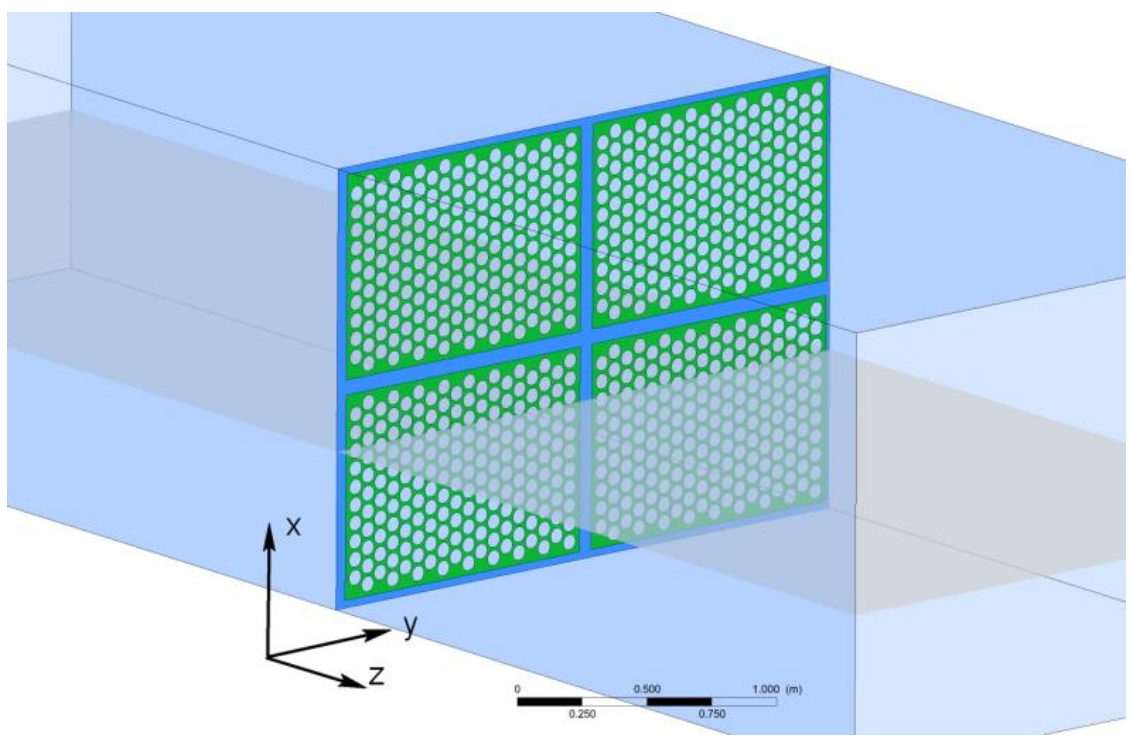

Figure 10. Part of geometrical model of the tunnel with panel plate including structural object; grey area represents the plane at $x=0.63 \mathrm{~m}$. 
Numerical studies were conducted for both the perforated plates panel and the porous core panel. Again, for the porous model, the coefficient $C_{2}$ was calculated from Equation (11). As previously, for both cases, the perforated plates panel and porous core panel velocities $u_{1}=5 \mathrm{~m} / \mathrm{s}$ and $u_{2}=10 \mathrm{~m} / \mathrm{s}$ were set as boundary conditions. Calculations in which the structural elements are included were performed for the cases: $f=0.40, f=0.50$, $f=0.55$ and $f=0.60$. Pressure drop through the perforated plate ( $10 D$ before and behind plate) was compared with pressure drop through the porous plate for the same average air velocity at inlet. Results are presented in Table 6 . The table also shows calculated velocity at the plane located at a distance of $10 D$ behind the plate, for both cases: the perforated plate and the porous plate. Relative error was calculated as follows

$$
R E=\left|\frac{\Delta_{\text {porous }}-\Delta_{\text {perforated }}}{\Delta_{\text {porous }}}\right| \cdot 100 \%
$$

Table 6. Numerical results of pressure drop for perforated plate and equivalent porous plate.

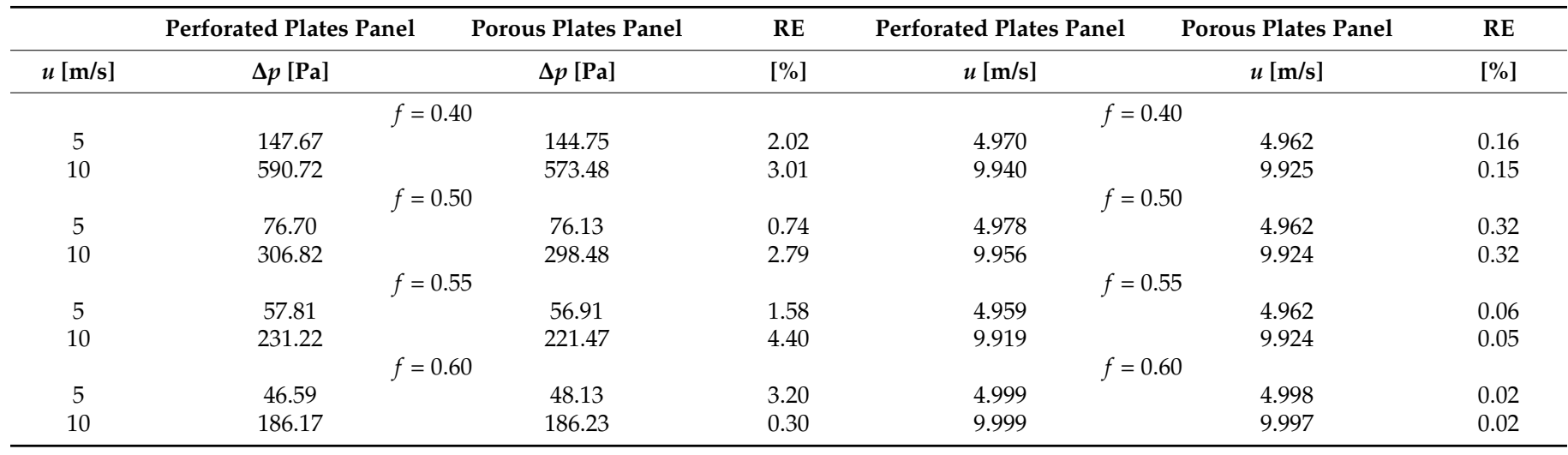

It can be seen from Table 6 that pressure drops for both panels have almost the same level. The relative error is less than $5 \%$. The average values of calculated velocities behind the plate are in very good agreement with a relative error less than $0.5 \%$. The important part in this simulation is velocity distribution. It is expected that structural elements will disturb the flow. In order to compare the velocity distribution between the plates, velocity magnitudes at 21 different levels ( $x$ coordinate in Figure 10) were analysed. One of the planes located at $x=0.63 \mathrm{~m}$ is shown in Figure 10, and flow direction is along the $z$ axis.

As was emphasised previously, the structural elements must be included in the model with porous core. The distance of the first row of holes from the plate edges of perforated plates is different for each case. As the open area ratio of the plate increases, the number of holes in the plate increases and the distance of the first row of holes from the plate edges decreases. Because the porous core has to replace a perforated plate of the various open area ratios, the equivalent area for the porous core valid for all tested plates has to be found. Note that the structural elements have different sizes for panels with porous cores, while for the perforated plate, panels have the same size regardless of the open area ratio $f$ (see Figure 11).

It is expected that in the porous core panel, the structural elements will disturb the flow, just like in the case of the panel with perforated plates. The pathlines obtained for both types of the panels are presented in Figure 12. The left-hand side figure presents the flow through the perforated panel, and the right-hand side figure presents the flow though porous core panel. In both figures, the vortices generated by the structural elements are visible. 


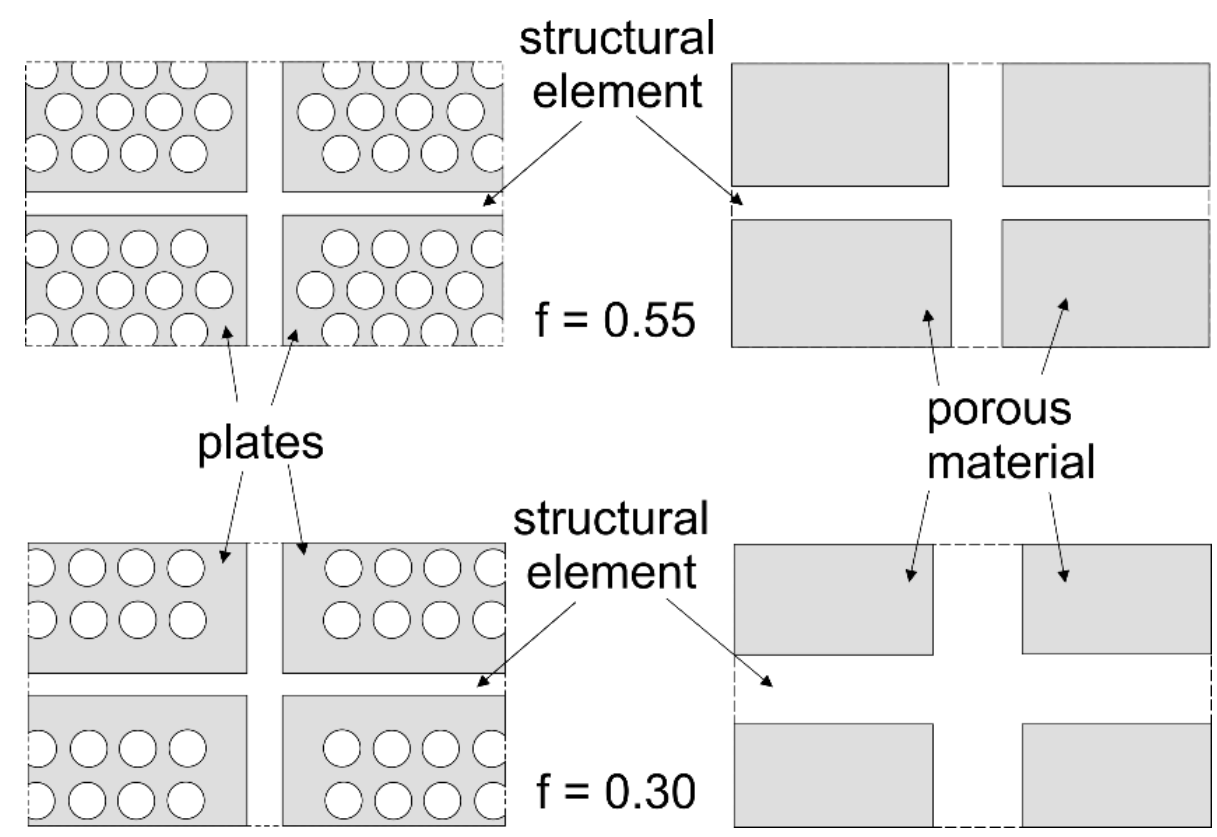

Figure 11. Perforated plate panel vs. porous plate panel for open area ratios $f=0.55$ and $f=0.30$.

Only a few exemplary results for different cases are shown in the paper. This is because of the large number of obtained results, and mostly because the results show similar trends and flow-fields for all cases. The top view of the pathlines on the plane located at $x=0.63 \mathrm{~m}$ (see the plane location in Figure 10) is presented in Figure 13a, while the view of the pathlines on the plane located at $50 \%$ height $(x=0.88 \mathrm{~m})$ is presented in Figure 13b. It can be seen that the structural elements in the porous core panel predict well the vortices behind the panel compared to the vortices observed in the flow through the perforated plate. In Figure 13b, the black line on the right-hand side of the plate represents the cross section used for qualitive validation shown in Figure 15.
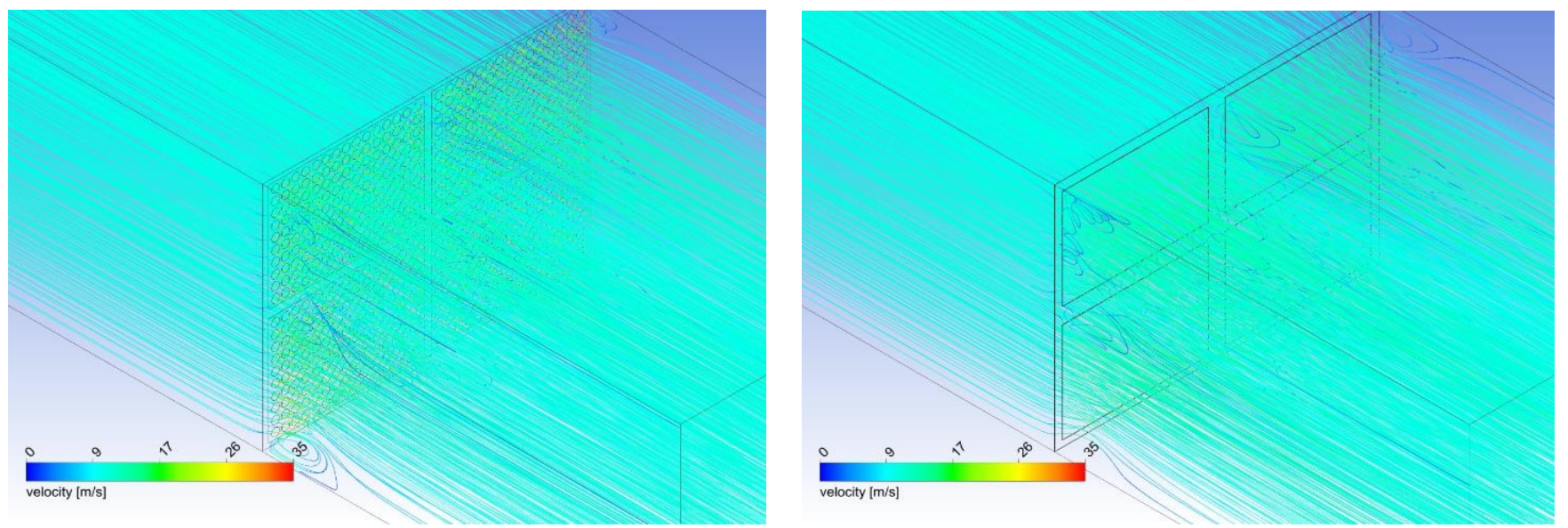

Figure 12. Isometric view on pathlines for four plate panels with open area ratio $f=0.40$ (left) and corresponding porous core (right), $u_{\text {inlet }}=10 \mathrm{~m} / \mathrm{s}$. 

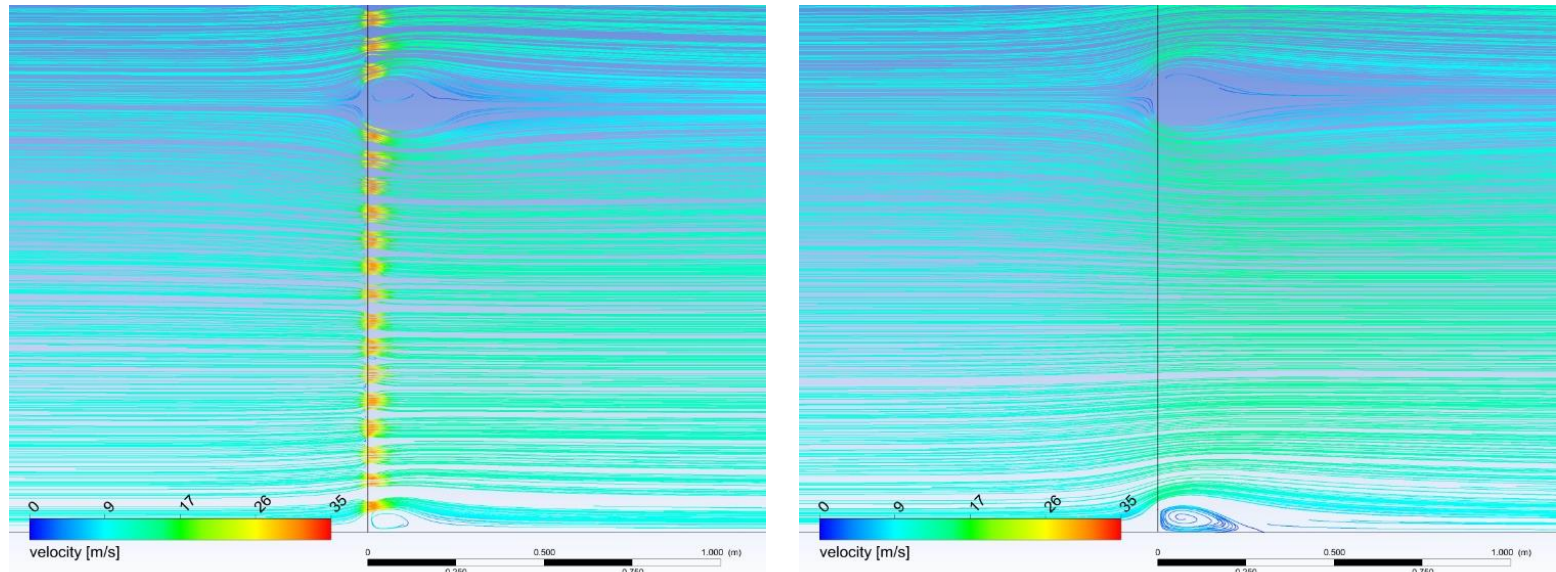

(a)

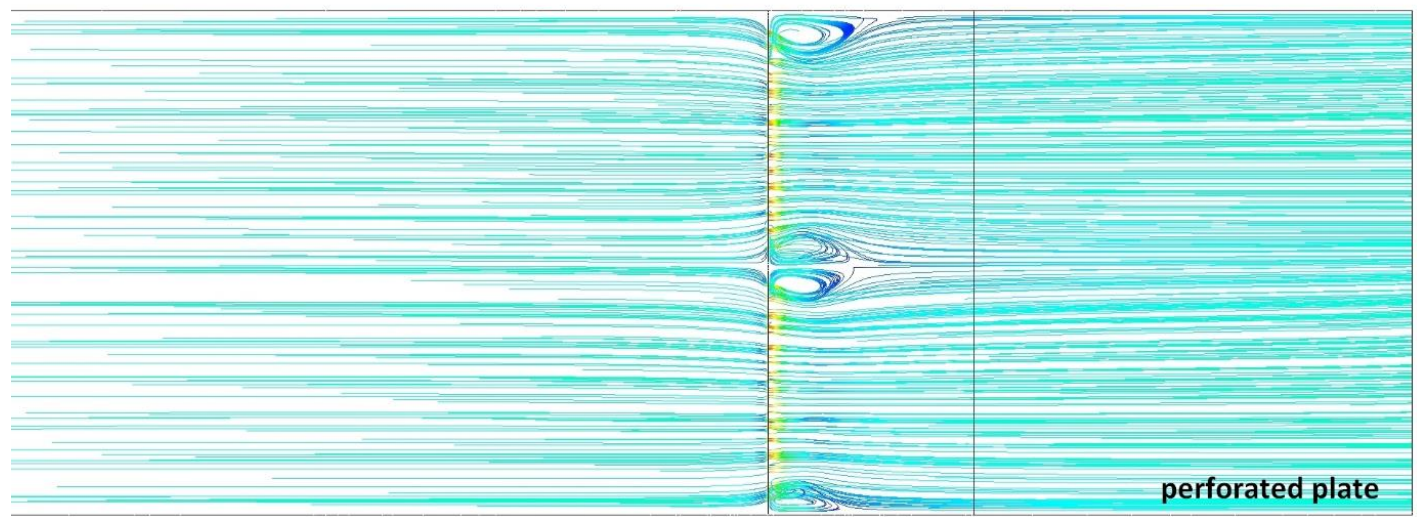

Velocity

15.0

13.8

12.7

11.5

10.4

9.2

8.1

6.9

5.8

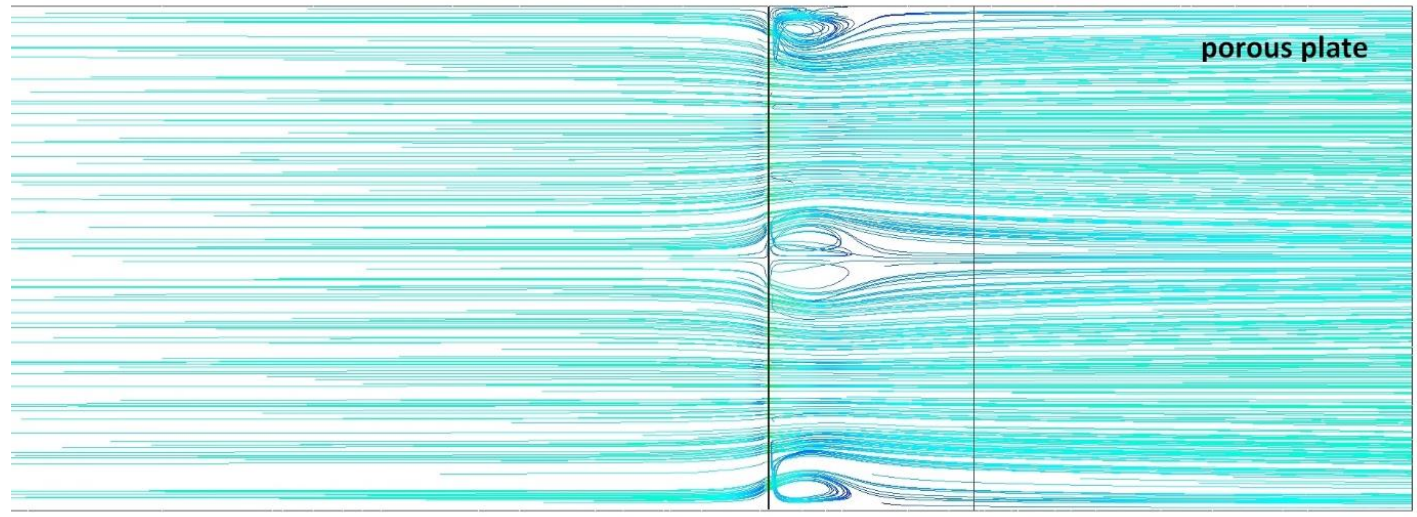

(b)

Figure 13. (a) Top view on pathlines on the plane located at $x=0.63 \mathrm{~m}$ for four plate panels with open area ratio $f=0.40$ (left) and corresponding porous core (right), $u_{\text {inlet }}=10 \mathrm{~m} / \mathrm{s}$. (b). Top view on pathlines on the plane located at $50 \%$ height $(x$ $=0.88 \mathrm{~m}$ ) for four plate panels with open area ratio $f=0.40$ and corresponding porous core $u_{\text {inlet }}=5 \mathrm{~m} / \mathrm{s}$.

Quantitative validation of velocity distribution is presented in Figure 14 for two exemplary lines, only for the case of $f=0.50$. Lines are located approximately at the middle of the first line of holes $(x=0.075 \mathrm{~m})$ and at $40 \%$ height of the tested model $(x=0.63 \mathrm{~m})$. The lower values of velocity magnitude in the middle of the distribution line (approximately $y=1.2 \mathrm{~m}$ ) result from the presence of the structural elements. The lower part of Figure 14 shows the relative errors for these cases. It is clear that the velocity profile for the porous 
plate fits well to the velocity profile for the perforated plane. As can be seen for the majority of the sample points, the relative error calculated from Equation (13) is in the range of $\pm 10 \%$. Higher discrepancy is observed for points in the vicinity of the model walls.

$$
R E=\left|\frac{u_{\text {porous }}-u_{\text {perforated }}}{u_{\text {porous }}}\right| \cdot 100 \%
$$

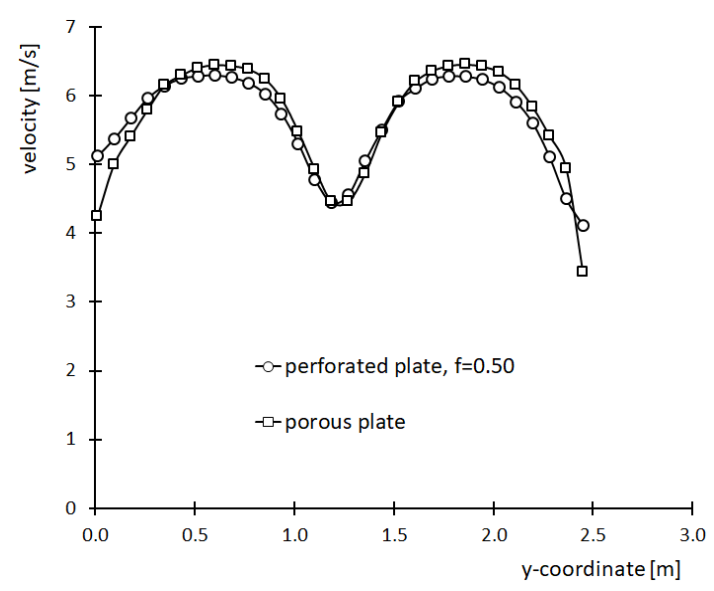

inlet velocity $u=5 \mathrm{~m} / \mathrm{s}, x=0.075 \mathrm{~m}$

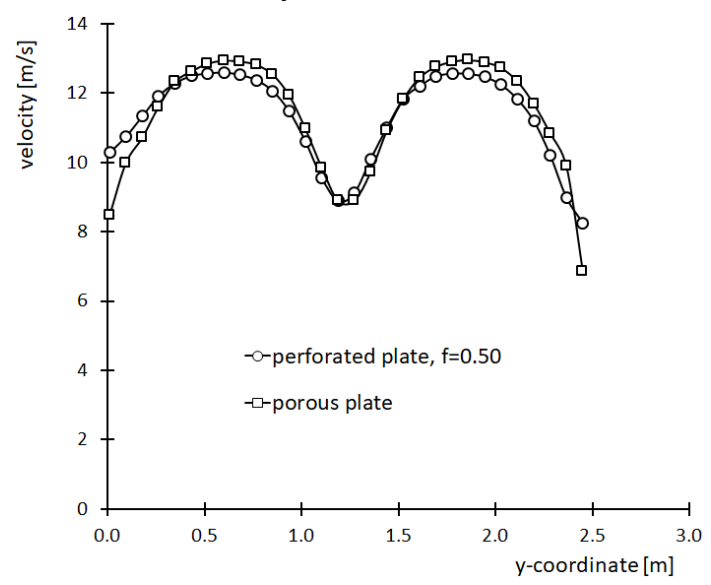

inlet velocity $u=10 \mathrm{~m} / \mathrm{s}, x=0.075 \mathrm{~m}$

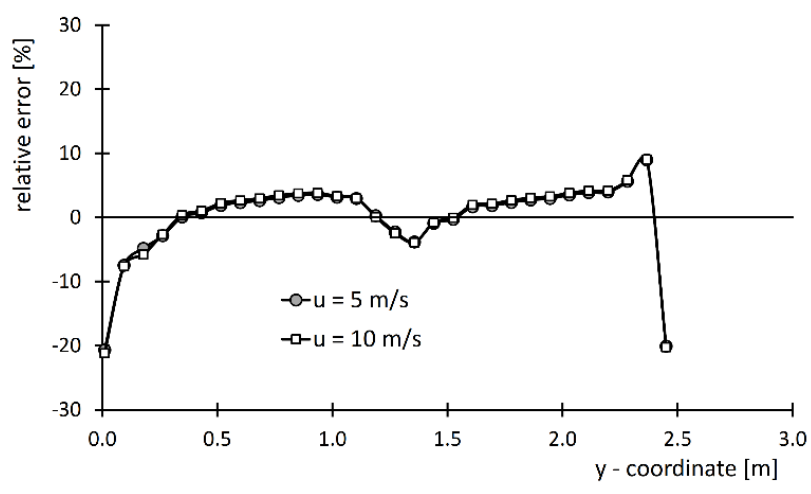

relative error at $x=0.075 \mathrm{~m}$

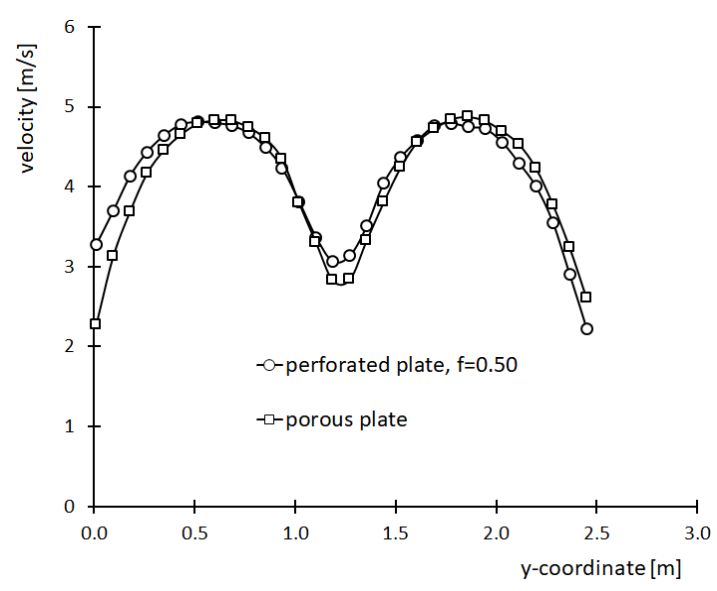

inlet velocity $u=5 \mathrm{~m} / \mathrm{s}, x=0.63 \mathrm{~m}$

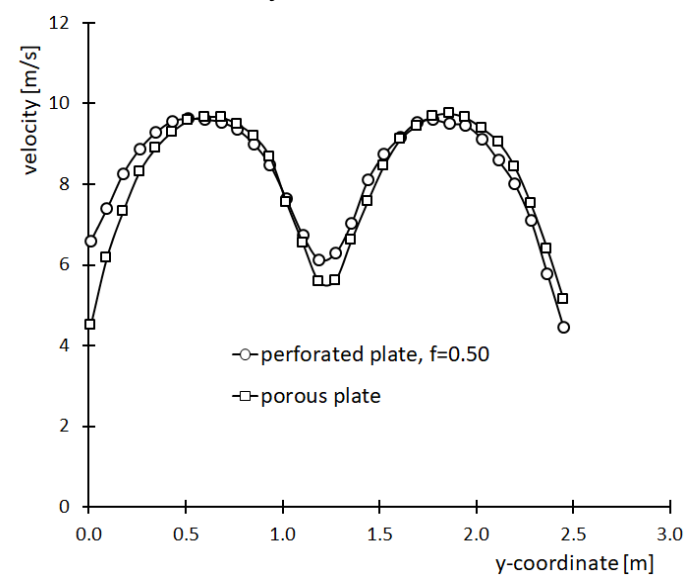

inlet velocity $u=10 \mathrm{~m} / \mathrm{s}, x=0.63 \mathrm{~m}$

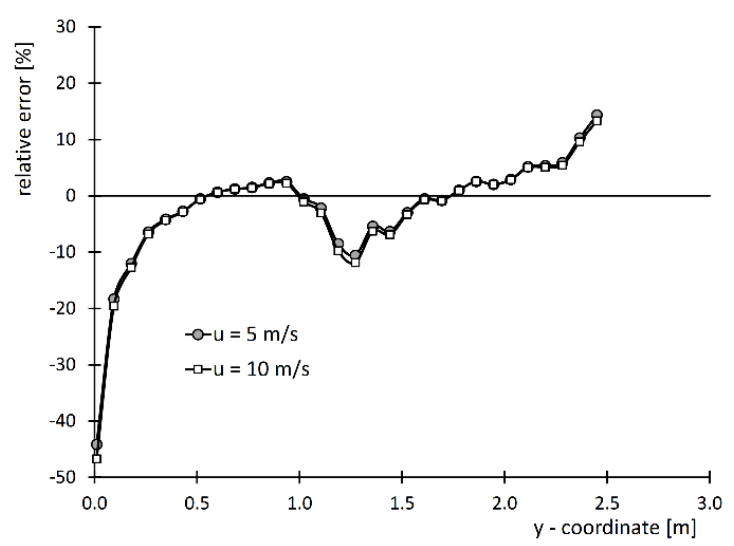

relative error at $x=0.63 \mathrm{~m}$

Figure 14. Velocity module profiles at cross-section $\mathrm{x}, f=0.50$, for inlet velocities $5 \mathrm{~m} / \mathrm{s}$ and $10 \mathrm{~m} / \mathrm{s}$. 
The velocity field for the case of $f=0.40$ and velocity $u=5 \mathrm{~m} / \mathrm{s}$ is shown in Figure 15a and for the case of $f=0.50$ and velocity $u=10 \mathrm{~m} / \mathrm{s}$ is shown in Figure 15b. Again, very good agreement between results is observed. All planes are located at a distance of $100 \mathrm{~cm}$ behind the plate. The velocity field for both cases is divided into four parts, which represent four plates. A maximum velocity of $u_{\max } \approx 6.5 \mathrm{~m} / \mathrm{s}$ for $f=0.40$ and $u_{\max } \approx 12 \mathrm{~m} / \mathrm{s}$ for $f=0.50$ in the middle of each plane was observed.

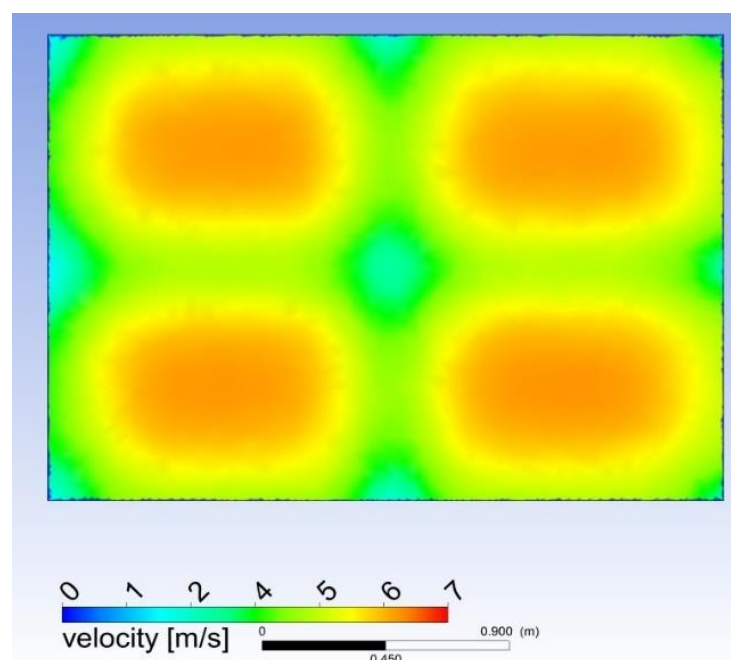

$f=0.40, u=5 \mathrm{~m} / \mathrm{s}-$ perforated plate
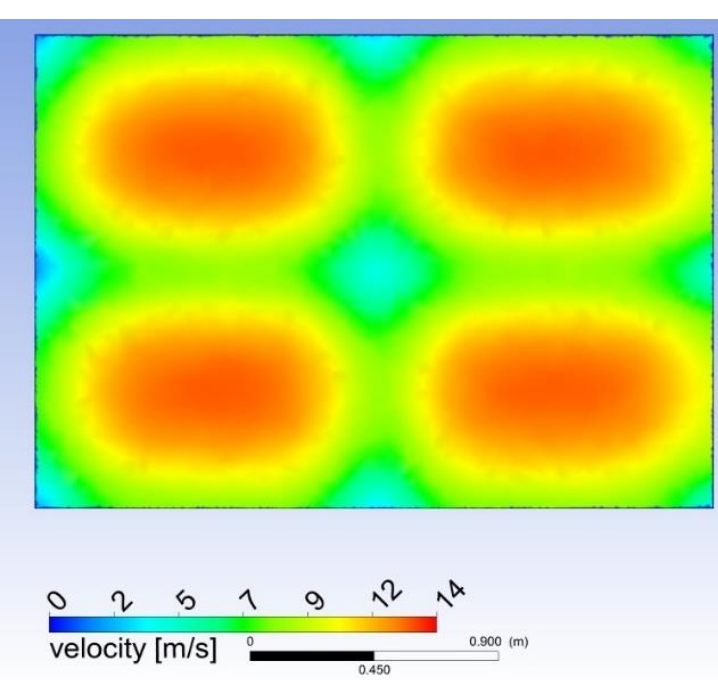

$f=0.50, u=10 \mathrm{~m} / \mathrm{s}-$ perforated plate
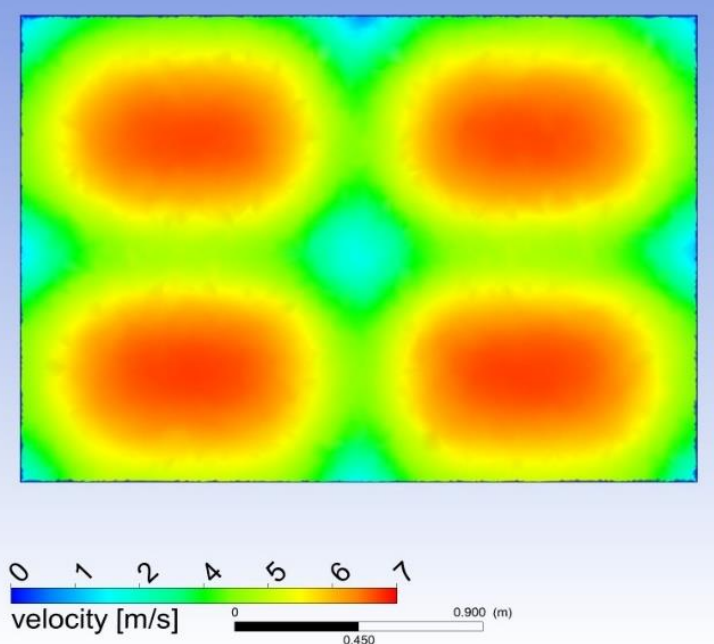

$f=0.40, u=5 \mathrm{~m} / \mathrm{s}-$ porous plate

(a)
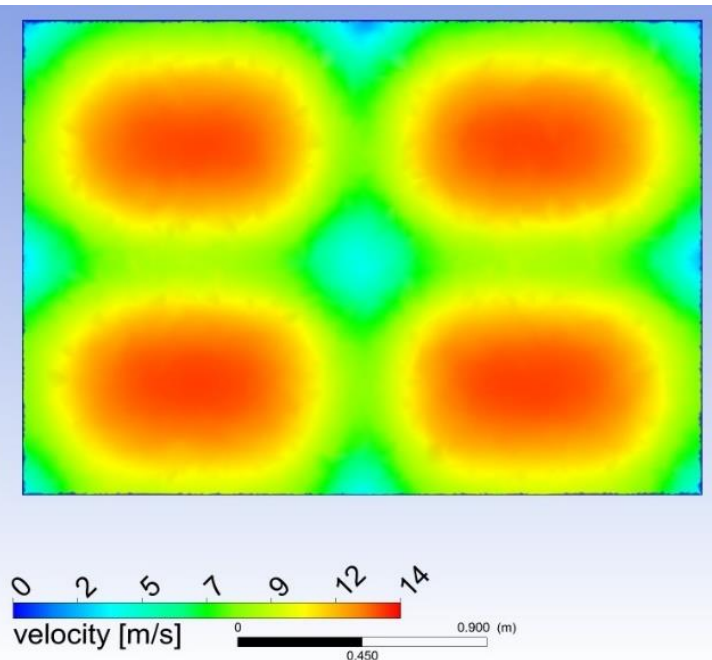

$$
f=0.50, u=10 \mathrm{~m} / \mathrm{s}-\text { porous plate }
$$

(b)

Figure 15. Velocity module field at distance of $100 \mathrm{~cm}$ behind the plates, $f=0.50$, for inlet velocities $5 \mathrm{~m} / \mathrm{s}$ and $10 \mathrm{~m} / \mathrm{s}$. (a) Velocity field for the perforated plate with open area ratio $f=0.40$ (left) and corresponding porous core (right), velocity inlet $u=5 \mathrm{~m} / \mathrm{s}$. (b) Velocity field for the perforated plate with open area ratio $f=0.50$ (left) and corresponding porous core (right), velocity inlet $u=10 \mathrm{~m} / \mathrm{s}$.

\section{Conclusions}

The following conclusions can be drawn on the basis of the obtained results:

- The paper presents the approach of the modelling of flow through such complex objects as large-scale perforated plates using the porous core model. The proposed 
method can be interesting and easy to apply by engineers for designing and optimising complex structures in which structural elements cannot be ignored. An example of such a structure is an ESP used in power technology.

- The proposed numerical modelling approach predicts well the air flow through the perforated plates of different open area ratios with use of the porous model. This can lead to a significant reduction in time and required computational resources for the design and modelling of the flow where homogeneity is required.

- Pressure drop through the perforated plate obtained from a CFD simulation fits the experimental pressure drop with an error less than $1 \%$. Pressure drop of the plates of the different open area ratios can be approximated by the mean of polynomial functions.

- Proposed correlation can be used for prediction of the internal resistance coefficient as a function of the plate open area ratio. The pressure drop through the porous core predicted by simulations using developed correlation differs from the pressure drop generated by a perforated plate by less than $20 \%$.

- Qualitative and quantitative obtained results in terms of velocity field and pressure drop across the plate show that the proposed approach has great potential for practical applications. As the next step, investigations into angular flow through the plates are proposed. This would allow the area of application of the proposed approach to be increased. In addition, the application of apparent porosity instead of the actual porosity may be investigated to further improve the proposed method.

Author Contributions: Conceptualization, D.B. and K.Ś.; methodology, K.Ś.; software, K.Ś; validation, K.Ś., J.K. and J.G.; formal analysis, D.B.; investigation, J.K.; resources, J.G.; data curation, D.B.; writing—original draft preparation, K.Ś.; writing—review and editing, K.Ś. and D.B.; visualization, J.K.; supervision, D.B.; project administration, D.B.; funding acquisition, D.B. All authors have read and agreed to the published version of the manuscript.

Funding: This research was funded by partially by Rafako S.A., grant number O/LP/0027/10 and partially within the statutory activities W/WM-IIM/1/2020 financed by Ministry of Education and Science. The APC was funded by W/WM-IIM/1/2020.

Institutional Review Board Statement: Not applicable.

Informed Consent Statement: Not applicable.

Data Availability Statement: Not applicable.

Acknowledgments: The authors would like to thank Łukasz Śliwiński from Rafako S.A. for providing the perforated plate for experimental investigation and Tomasz Ochrymiuk from the Szewalski Institute of Fluid-Flow Machinery Polish Academy of Sciences for helping with CFD simulation.

Conflicts of Interest: The authors of the proposed paper declare no conflict of interest.

\section{Nomenclature}

$A_{O}, A_{C} \quad$ surface area of holes, total surface area of the plate, respectively, $\mathrm{m}^{2}$

$C_{2} \quad$ internal resistant coefficient, $\mathrm{m}^{-1}$

$D$ diameter, $\mathrm{m}$

$f \quad$ open area ratio of the plate,

$p \quad$ pressure, $\mathrm{Pa}$

$\mathrm{P}$ porosity,

u velocity, $\mathrm{m} / \mathrm{s}$

$\alpha \quad$ permeability, $\mathrm{m}^{2}$

$\delta \quad$ thickness of the plate, $\mathrm{m}$

$\rho \quad$ density, $\mathrm{kg} / \mathrm{m}^{3}$

$\mu \quad$ dynamic air viscosity, Pa.s 


\section{References}

1. Pistoresi, C.; Fan, Y.; Luo, L. Numerical study on the improvement of flow distribution uniformity among parallel mini-channels. Chem. Eng. Process. Process Intensif. 2015, 95, 63-71. [CrossRef]

2. Mazur, M.; Bhatelia, T.; Kuan, B.; Patel, J.; Webley, P.A.; Brandt, M.; Pareek, V.; Utikar, R. Additively manufactured, highly-uniform flow distributor for process intensification. Chem. Eng. Process. Process Intensif. 2019, 143, 107595. [CrossRef]

3. Govindan, B.; Jakka, S.C.B.; Radhakrishnan, T.K.; Saashi, K.G.N.; Tiwari, A.K.; Manoj, K.S.; Tulsyan, P.; Kalburgi, A.K.; Balasubramanya, H.A. CFD approach in design of effective distributor for uniform dispersion of cohesive ultrafine particles in a downer reactor. Chem. Eng. Process. Process Intensif. 2020, 157, 108138. [CrossRef]

4. Miller, B.G. Advanced flue gas dedusting systems and filters for ash and particulate emissions control in power plants. In Woodhead Publishing Series in Energy: Advanced Power Plant Materials, Design and Technology; Dermot Roddy, D., Ed.; Woodhead Publishing: Sawston, UK, 2010; pp. 217-243.

5. European Parliament. Commission Implementing Decision (EU) 2017/1442 of 31 July 2017 under Directive 2010/75/EU. 2017. Available online: EUR-Lex-32017D1442-EN-EUR-Lex(europa.eu) (accessed on 27 September 2021).

6. Swaminathan, M.R.; and Mahalakshimi, M.W. Numerical modelling of flow though perforated plates applied to electrostatic precipitators. J. Appl. Sci. 2010, 10, 2426-2432. [CrossRef]

7. The Institute of Clean Air Companies (1997), Electrostatic Precipitator Gas Flow Model Studies (rev. 2004) Guidelines for Modeling Gas Flows in Electrostatic Precipitators in Order to Ensure Flow Uniformity in the Finished Unit. Publication ICAC EP-7, Electronic Document. Available online: https://cdn.ymaws.com/www.icac.com/resource/resmgr/Standards_WhitePapers/EP7_final.pdf (accessed on 27 September 2021).

8. Xu, Y.; Deng, B.; Zhang, H.; Chen, X. Numerical simulation of electrostatic field and flow field in an electro-static precipitator. J. Air Pollut. Health 2019, 4, 87-98. [CrossRef]

9. Kaiser, S.; Fahlenkamp, H. CFD Modelling of the Electrical Phenomena and the Particle Precipitation Process of Wet ESP in Coaxial Wire-tube Configuration. Int. J. Plasma Environ. Sci. Technol. 2011, 5, 103-109.

10. Heidarbeig, M.; Mohebbi, A. CFD Modeling of Particulate Pollutants Removal by Electrostatic Precipitator (ESP). In Proceedings of the 8th International Chemical Engineering Congress \& Exhibition (IChEC 2014), Kish, Iran, 24-27 February 2014.

11. Haque, S.M.E.; Rasul, M.G.; Khan, M.M.K.; Deev, A.V.; Subaschandar, N. A Numerical Model of an Electrostatic Precipitator. In Proceedings of the 16th Australasian Fluid Mechanics Conference, Gold Coast, Australia, 3-7 December 2007; pp. $1050-1054$.

12. Scodras, G.; Kaldis, S.P.; Sofialidis, D.; Faltsi, O.; Grammelis, P.; Sakellaropoulos, G.P. Particulate removal via electrostatic precipitators-CFD simulation. Fuel Process. Technol. 2006, 87, 623-631. [CrossRef]

13. Arif, S.; Branken, D.J.; Everson, R.C.; Neomagus, H.W.J.P.; le Grange, L.A.; Arif, A. CFD modeling of particle charging and collection in electrostatic precipitators. J. Electrost. 2016, 84, 10-22. [CrossRef]

14. Guo, B.Y.; Hou, Q.F.; Yu, A.B.; Li, L.F.; Guo, J. Numerical modelling of the gas flow through perforated plates. Chem. Eng. Res. Des. 2013, 91, 403-408. [CrossRef]

15. Yusop, A.F.; Mamat, R.; Mat Yasin, M.H.; Suhaimi, S. Effects of the Inlet Velocity Profiles on the Prediction of Velocity Distribution inside an Electrostatic Precipitator. Int. J. Comput. Electr. Eng. 2014, 6, 64-66. [CrossRef]

16. Kouropoulos, G. Two-Dimensional Computational Simulation Flow Of Exhaust Gases Passing Inside An Electrostatic Precipitator. J. Urban Environ. Eng. 2018, 10, 106-112. [CrossRef]

17. Celik, N.; Bayazit, Y.; Turgut, E.; Sparrow, E.M. Design Analysis Of Fluid-Flow Through Perforated Plates. Therm. Sci. 2018, 22, 3091-3098. [CrossRef]

18. Haque, S.M.E.; Rasul, M.G.; Deev, A.; Khan, M.M.K.; Zhou, J. The influence of flow distribution on the performance improvement of electrostatic precipitator. In Proceedings of the 10th International Conference on Electrostatic Precipitation (ICESP), Cairns, Australia, 26-27 June 2006. Paper No. 2A1.

19. Haque, S.M.E.; Rasul, M.G.; Deev, A.; Khan, M.M.K.; Subaschandar, N. Flow simulation in an electrostatic precipitator of a thermal Power plant. Appl. Therm. Eng. 2009, 29, 2037-2042. [CrossRef]

20. ANSYS Fluent User Guide, Release 14.0; ANSYS, Inc.: Canonsburg, PA, USA, 2011.

21. Butrymowicz, D.; Śliwiński, Ł.; Śmierciew, K.; Karwacki, J.; Ochrymiuk, T.; Lackowski, M.; Przybyliński, T.; Antes, T. Indirect method of numerical modelling of perforated plates in electrostatic precipitators. In Proceedings of the 12th International Conference on Boiler Technology ICBT 2014, Szczyrk, Poland, 21-24 October 2014; pp. 111-123.

22. Hou, Q.F.; Guo, B.Y.; Li, L.F.; Yu, A.B. Numerical Simulation of Gas Flow in An Electrostatic Precipitator. In Proceedings of the 7th International Conference on CFD in the Minerals and Process Industries, CSIRO, Melbourne, Australia, 9-11 December 2009. 